Review

\title{
Guidelines for the Management of Unilateral Vocal Fold Paralysis From the Korean Society of Laryngology, Phoniatrics and Logopedics
}

\author{
Korean Society of Laryngology, Phoniatrics and Logopedics Guideline Task Force; Chang Hwan Ryu ${ }^{1}$ (i)

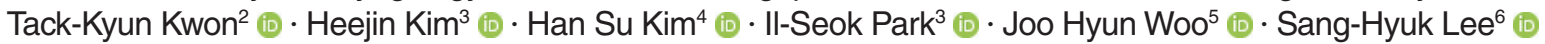

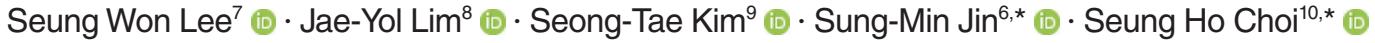 \\ Department of Otorhinolaryngology-Head Neck Surgery, ${ }^{1}$ National Cancer Center, Goyang; ${ }^{2}$ Seoul National University College of Medicine, \\ Seoul; ${ }^{3}$ Dongtan Sacred Heart Hospital, Hallym University College of Medicine, Hwaseong; ${ }^{4}$ Ewha Womans University College of Medcine, \\ Seoul; ${ }^{5}$ Gachon University College of Medicine, Incheon; ${ }^{6}$ Kangbuk Samsung Hospital, Sungkyunkwan University School of Medicine, Seoul; \\ ${ }^{7}$ Soonchunhyang University College of Medicine, Bucheon; ${ }^{8}$ Yonsei University College of Medicine, Seoul; ${ }^{9}$ Department of Speech-Language \\ Pathology, Dongshin University, Naju; ${ }^{10}$ Asan Medical Center, University of Ulsan College of Medicine, Seoul, Korea
}

The Korean Society of Laryngology, Phoniatrics and Logopedics appointed a task force to establish clinical practice guidelines for the management of unilateral vocal fold paralysis (UVFP). These guidelines cover a comprehensive range of management-related factors, including the diagnosis and treatment of UVFP, and provide in-depth information based on current, up-to-date knowledge. Detailed evidence profiles are provided for each recommendation. The CORE databases, including OVID Medline, Embase, the Cochrane Library, and KoreaMed, were searched to identify all relevant papers, using a predefined search strategy. When insufficient evidence existed, expert opinions and Delphi questionnaires were used to fill the evidence gap. The committee developed 16 evidence-based recommendations in six categories: initial evaluation (R1-4), spontaneous recovery (R5), medical treatment (R6), surgical treatment (R7-14), voice therapy (R15), and aspiration prevention (R16). The goal of these guidelines is to assist general otolaryngologists and speech-language pathologists who are primarily responsible for treating patients with UVFP. These guidelines are also intended to facilitate understanding of the condition among other health-care providers, including primary care physicians, nurses, and policy-makers.

Keywords. Functional Recovery; Guideline; Laryngeal Framework Surgery; Laryngoplasty; Voice Training; Vocal Fold Paralysis

- Received March 20, 2020

Accepted April 13, 2020

- Corresponding author: Seung Ho Choi

Department of Otorhinolaryngology-Head Neck Surgery, Asan Medical

Center, University of Ulsan College of Medicine, 88 Olympic-ro 43-gil,

Songpa-gu, Seoul 05505, Korea

Tel: +82-2-3010-3710, Fax: +82-2-489-2773

E-mail: shchoi@amc.seoul.kr

- Co-Corresponding author: Sung-Min Jin

Department of Otorhinolaryngology-Head Neck Surgery, Kangbuk Samsung

Hospital, Sungkyunkwan University School of Medicine, 29 Saemunan-ro,

Jongno-gu, Seoul 03181, Korea

Tel: +82-2-2001-2266, Fax: +82-2-2001-2273

E-mail: strobojin@hanmail.net

*These authors contributed equally to this work as corresponding authors.

\begin{abstract}
AIM
The primary purpose of these guidelines is to promote optimal health outcomes for patients with unilateral vocal fold paralysis (UVFP). These guidelines cover comprehensive aspects of the management of UVFP, including diagnostic parameters and treatment options, to provide in-depth information based on current and up-to-date knowledge. Detailed evidence profiles were provided for each recommendation. When insufficient evidence existed, expert opinions and Delphi questionnaires were used to fill the evidence gap.
\end{abstract}

\section{BURDEN}

Because of the complex causes of UVFP, its reported incidence

Copyright $\odot 2020$ by Korean Society of Otorhinolaryngology-Head and Neck Surgery.

This is an open-access article distributed under the terms of the Creative Commons Attribution Non-Commercial License (https://creativecommons.org/licenses/by-nc/4.0)

which permits unrestricted non-commercial use, distribution, and reproduction in any medium, provided the original work is properly cited. 
differs across reports. The actual incidence of UVFP remains unknown, but its incidence in the general population is estimated at approximately 5 per 100,000 per year [1]. With the increased frequency of thyroid and cervical spine surgery, the incidence of UVFP due to iatrogenic causes has risen sharply. The incidence has been reported to be $2 \%-10 \%$ after thyroid surgery and up to $21 \%$ after cervical spine surgery [2-4]. Most patients with UVFP complain of voice changes. Due to the crucial role of phonation in communication, patients with UVFP can experience social withdrawal and psychological effects [5-7], and it is well recognized that dysphonia promotes withdrawal, anxiety, and depression [8]. UVFP also increases the risk of aspiration, which may result in life-threatening conditions, such as aspiration pneumonia.

\section{DEFINITION OF TERMS}

Currently, vocal fold paralysis (VFP) is also variously termed vocal cord palsy, vocal cord paralysis, vagal paralysis, and recurrent laryngeal neuropathy. Vocal cord paralysis is the most commonly used of these terms, and it is the only one listed as a MeSH term in the National Library of Medicine controlled vocabulary thesaurus used for indexing articles for Medline. However, vocal folds consist of two pairs of membranes, with an outer cover and inner body. Contact and vibration of these two folds generates sound during phonation. Thus, the term VFP more precisely reflects the anatomical and pathophysiological characteristics of the condition. Therefore, in these guidelines, the committee described the condition of a paralyzed vocal fold as VFP [9].

\section{INTENDED USERS}

These guidelines are primarily intended for general otolaryngol-

\section{H I G H L I G G H T S}

- These guidelines cover a comprehensive range of management factors, including the diagnosis and treatment of unilateral vocal fold paralysis (UVFP), and provide in-depth information based on current, up-to-date knowledge.

- Detailed evidence profiles are provided for each recommendation.

- The committee developed 16 evidence-based recommendations in six categories: initial evaluation (R1-4), spontaneous recovery (R5), medical treatment (R6), surgical treatment (R714), voice therapy (R15), and aspiration prevention (R16).

- These guidelines are intended to facilitate understanding of the clinical management of UVFP among general otolaryngologists, speech-language pathologists, and other health-care providers, including primary care physicians, nurses, and policy-makers. ogists and speech-language pathologists (SLPs) who treat patients with UVFP. These guideline also have the goal of promoting an improved understanding of the management of UVFP by other health-care providers, including primary care physicians, nurses, and health policy-makers.

\section{MATERIALS AND METHODS}

\section{Organization of the committee}

The chairman (SHC) of the task force for the development of guidelines for the management of UVFP was recommended by the Korean Society of Laryngology, Phoniatrics and Logopedics (KSLPL). The chairman led a committee that included one secretary (CHR) and nine members (TKK, HJK, HSK, ISP, JHW, SHL, SWL, JYL, and SMJ). The guideline committee had complete editorial independence from the KSLPL. The kick-off meeting of the committee was held on June 12, 2017. The guideline committee participated in a conference call to review and evaluate the development of various recommendations and guidelines at regularly scheduled, face-to-face meetings, with 1-2-month intervals.

\section{Selection of key questions}

The goal of this project was to develop comprehensive management guidelines regarding UVFP, including initial assessment and treatment. Accordingly, we divided topics into six categories: initial evaluation, spontaneous recovery, medical treatment, surgical treatment, voice therapy, and aspiration prevention. The committee did not address the management of bilateral VFP because bilateral VFP may cause emergency situations requiring rapid airway management; however, the details of these situations may differ according to the patient's circumstances and the physician's experience. The committee therefore agreed that the management of bilateral VFP may not be suitable for standardized guidelines. Before fine-tuning the key questions, the committee held a symposium to debate the management of UVFP on October 20, 2017, at the fall meeting of the Korean Otorhinolaryngology Society. The final key question list comprised 16 key questions. The key questions for each category are listed in Table 1.

\section{Literature search and quality assessment}

After establishing the key questions, the committee reached a consensus about the keywords to searching for a systematic review of the key questions. This literature search was performed on May 1, 2018. The CORE databases, including OVID Medline, Embase, Cochrane Library, and KoreaMed, were searched for all available papers using the same search strategy (Supplementary Tables 1-3). The results of these literature searches were saved in Endnote X8 (Thomson Reuters, New York, NY, USA). After removing duplicates, two independent committee members per- 
formed a primary review for selecting relevant articles according to the title/abstract. The inclusion criteria were as follows: (1) human studies, (2) article publication type, and (3) English-language text. All committee members performed a full-text review to determine the papers for final inclusion. The search strategy,

Table 1. Organization of the guidelines for management of UVFP

\begin{tabular}{|c|c|}
\hline Section and subsection & Item \\
\hline \multicolumn{2}{|l|}{ Guidelines for management of UVFP } \\
\hline \multicolumn{2}{|l|}{ Initial evaluation } \\
\hline KQ 1. Role of laryngoscopy and stroboscopy & R1 \\
\hline KQ 2. Role of voice assessment & $\mathrm{R} 2$ \\
\hline KQ 3. Role of imaging studies & R3 \\
\hline KQ 4. Role of electromyography & R4 \\
\hline \multicolumn{2}{|l|}{ Spontaneous recovery } \\
\hline KQ 5. Spontaneous recovery & R5 \\
\hline \multicolumn{2}{|l|}{ Medical treatment } \\
\hline KQ 6. Role of medical treatment (steroids) & $\mathrm{R} 6$ \\
\hline \multicolumn{2}{|l|}{ Surgical treatment } \\
\hline KQ 7. Selection of injection materials & $\mathrm{R} 7$ \\
\hline KQ 8. Selection of injection technique & R8 \\
\hline KQ 9. Timing of injection laryngoplasty & $\mathrm{R} 9$ \\
\hline KQ 10. Follow-up after injection laryngoplasty & R10 \\
\hline KQ 11. Voice rest after injection laryngoplasty & $\mathrm{R} 11$ \\
\hline KQ 12. Preferred injection laryngoplasty in permanent UVFP & $\mathrm{R} 12$ \\
\hline $\begin{array}{l}\text { KQ 13. Preferred arytenoid adduction with medialization } \\
\text { thyroplasty }\end{array}$ & $\mathrm{R} 13$ \\
\hline KQ 14. Role of intraoperative reinnervation & R14 \\
\hline \multicolumn{2}{|l|}{ Voice therapy } \\
\hline KQ 15. Role of voice therapy & R15 \\
\hline \multicolumn{2}{|l|}{ Aspiration prevention } \\
\hline $\begin{array}{l}\text { KQ 16. Role of medialization surgical procedures for reduc- } \\
\text { ing aspiration }\end{array}$ & $\mathrm{R} 16$ \\
\hline
\end{tabular}

UVFP, unilateral vocal fold paralysis. number of retrieved papers, and search results are listed in Supplementary Table 1. Manual searches were also performed for articles published in Korean or from reference lists.

\section{Quality assessment of the literature and grades of recommendations and evidence levels}

The quality of evidence for use in these guidelines was assessed using the American College of Physicians (ACP) guideline grading system, which involves an in-depth appraisal before generating recommendations (Tables 2 and 3) [10]. As there is a lack of high-quality of randomized controlled trials (RCTs) in the field of UVFP management, we classified well-designed meta-analyses and systematic reviews as high-quality evidence. The Risk of Bias Assessment tool for Nonrandomized Studies (RoBANS, ver 1.5) was used for quality assessment of non-critical control studies (non-RCTs and observational studies), while A Measurement Tool to Assess the Methodological Quality of Systematic Reviews (AMSTAR) was used to assess systematic reviews and meta-analyses [11,12]. The ACP grading systems use two basic levels of recommendation (strong and weak), the simplicity of which facilitates easy interpretation by readers. For controversial issues with inconsistent or insufficient evidence, if it was not

Table 3. Level of evidence

\begin{tabular}{lc}
\hline Term & \multicolumn{1}{c}{ Definition } \\
\hline High-quality evidence & $\begin{array}{r}\text { RCT without important limitations or } \\
\text { overwhelming evidence from } \\
\text { observational study }\end{array}$ \\
Moderate-quality evidence & RCT with important limitations or strong \\
Low-quality evidence & Observational studies/case studies \\
\hline
\end{tabular}

$\mathrm{RCT}$, randomized controlled trial.

Table 2. Interpretation of the American College of Physicians grading system

\begin{tabular}{|c|c|c|c|}
\hline Grade of recommendation & Benefit vs. risks and burdens & Interpretation & Implication \\
\hline $\begin{array}{l}\text { Strong recommendation } \\
\text { High quality of evidence } \\
\text { Moderate quality of evidence } \\
\text { Low quality of evidence }\end{array}$ & $\begin{array}{l}\text { Benefits clearly outweigh risks } \\
\text { and burden or vice versa. }\end{array}$ & $\begin{array}{l}\text { Strong recommendation, can apply to } \\
\text { most patients in most circumstances } \\
\text { without reservation. } \\
\text { Strong recommendation, but may } \\
\text { change when higher-quality } \\
\text { evidence becomes available. }\end{array}$ & $\begin{array}{l}\text { For patients: most would want the } \\
\text { recommended course and only a small } \\
\text { proportion would not. } \\
\text { For clinicians: most patients should receive } \\
\text { the recommended course of action. }\end{array}$ \\
\hline $\begin{array}{l}\text { Weak recommendation } \\
\text { High quality of evidence } \\
\text { Moderate quality of evidence } \\
\text { Low quality of evidence }\end{array}$ & $\begin{array}{l}\text { Benefits closely balanced with } \\
\text { risk and burden. } \\
\text { Uncertainty in the estimates of } \\
\text { benefits, risks, and burden; } \\
\text { benefits, risks, and burden } \\
\text { may be closely balanced. }\end{array}$ & $\begin{array}{l}\text { Weak recommendation, best action } \\
\text { may differ depending on } \\
\text { circumstances or patients' or societal } \\
\text { values. } \\
\text { Very weak recommendation, other } \\
\text { alternatives may be reasonable. }\end{array}$ & $\begin{array}{l}\text { For patients: most would want the } \\
\text { recommended course of action but some } \\
\text { would not. A decision may depend on an } \\
\text { individual's circumstances. } \\
\text { For clinicians: different choices will be } \\
\text { appropriate for different patients, and a } \\
\text { management decision consistent with a } \\
\text { patient's values, preferences, and } \\
\text { circumstances should be reached. }\end{array}$ \\
\hline $\begin{array}{l}\text { No recommendation } \\
\text { Insufficient evidence }\end{array}$ & $\begin{array}{l}\text { Balance of benefits and risks } \\
\text { cannot be determined. }\end{array}$ & $\begin{array}{l}\text { Insufficient evidence to recommend } \\
\text { for or against routinely providing the } \\
\text { service. }\end{array}$ & $\begin{array}{l}\text { For patients: decisions based on evidence } \\
\text { from scientific studies cannot be made. } \\
\text { For clinicians: decisions based on evidence } \\
\text { from scientific studies cannot be made. }\end{array}$ \\
\hline
\end{tabular}


possible to determine the benefits and harms, a decision of "no recommendation" was made.

\section{Consensus regarding recommendations and manuscript development}

The Delphi method was used to establish consensus. Seventeen recommendations with 28 sub-recommendations were distributed to a panel of experts in the Delphi round. Sixty laryngologists, each with more than 10 years' experience, were invited to form the panel of experts. The Delphi questionnaire and a draft of the guidelines were sent to the panel members electronically. The panel members were asked to respond to each recommendation with "fully agree," "agree," "neither agree nor disagree," "disagree," or "totally disagree." A recommendation was finally accepted if more than two-thirds of the panel members responded with "fully agree" or "agree." The Delphi round continued for 2 months and 40 laryngologists (two-thirds of the panel) answered the questions. Only one recommendation (the key question regarding the role of re-innervation in chronic recurrent laryngeal nerve $[R L N]$ injury) failed to achieve agreement of more than two-thirds of the panel in the Delphi round.This recommendation was discarded from the manuscript (Supplementary Table 4).

\section{Limitations of guideline development}

As the guidelines mainly focused on UVFP, very few well-designed studies with high-quality evidence were available. Many recommendations were drawn from non-critical control studies. Another drawback was that the amount of data from Korean studies was insufficient to make nation-specific recommendations. To establish guidelines that would best address the situation in Korea, a multicenter approach to the publication of Korean treatment data is needed.

\section{Plan for release and update of guidelines}

The guidelines will be published in an open access journal to ensure wide access to its content, and the publication of these guidelines will be posted on the homepage of the KSLPL. The guideline development task force will continue to work as a special committee of the KSLPL. The guidelines will be revised every 3-5 years to integrate new clinical data and advances in diagnostic and therapeutic strategies.

\section{GUIDELINES FORTHE MANAGEMENT OF UVFP}

\section{A. Initial evaluation}

\section{KQ 1. What are the roles of laryngoscopy and stroboscopy in UVFP?}

\section{Recommendation 1}

(A) Laryngoscopy is an essential diagnostic tool for confirming the immobility of the vocal fold (strong recommen- dation, high-quality evidence).

(B) Stroboscopy is helpful for evaluating phonatory glottal closure, the mucosal wave, and the difference in level between the vocal folds (weak recommendation, lowquality evidence).

\section{Supporting text}

Physicians should visualize the larynx and perform appropriate history-taking and a physical examination of patients with dysphonia. UVFP is routinely identified and characterized through visualization of the larynx. With the development of optical systems, it has become a routine procedure to document all laryngeal findings as an image or video. In general, combining different visualization methods, including laryngoscopy and stroboscopy, allows us to gather extensive information about laryngeal structure and function [13].

Through direct visualization, physicians are not only able to observe vocal fold mobility, but also the degree of glottal closure, vocal fold bowing and shortening, and saliva pooling, as well as the possible cause of UVFP. In particular, glottic insufficiency, vocal fold bowing, and saliva pooling seem to show the most agreement among laryngoscopic findings [13].

Endoscopic visualization can be limited by supraglottal hyperactivity to overcome glottal incompetence [14-18]. Paralyzed vocal folds tend to become atrophic due to motor denervation, and are consequently shortened, which may cause anterior rotation of the arytenoid [19]. Hiramatsu et al. [20] reported that 91\% of patients with UVFP demonstrated a displaced arytenoid complex on three-dimensional computed tomography (CT), while $100 \%$ of these patients demonstrated caudal displacement. In these cases, flexible laryngoscopy permits better visualization of the vocal fold than does a mirror or rigid laryngoscopy. Flexible laryngoscopy facilitates an examination that is less operator- and/or patient-dependent [21].

Early studies suggested that the position and shape of the vocal fold may be indicative of the integrity of the vagus nerve [22, 23]. However, with the increasing knowledge of the neuropathophysiology of UVFP, it was recognized that the position of the vocal fold does not clarify the location of the lesion [19]. Others have suggested that the position of a false vocal fold may be informative, but this is also controversial [20].

However, even in cases with a minor glottic gap, the patient may find it difficult to produce durable phonation. The duration of phonatory closure is a crucial factor in the intensity of regulation, and insufficient duration may hamper daily conversation, even in the absence of a notable glottal gap [24]. In these situations, patients' vocal function may be overlooked by assessments using laryngoscopy.

Videostroboscopy has become the gold standard for assessing mucosal phonatory glottal closure [25]. Stroboscopy is not necessary to visualize the relatively slow medial and lateral move- 
ments of the vocal folds. The most common findings, other than incomplete glottal closure, include phase asymmetry and irregular mucosal waves [26,27]. Sercarz et al. [26] assessed 20 patients with untreated UVFP and found asymmetric mucosal wave vibration in all cases, with the non-paralyzed vocal cord showing greater amplitude and speed. Wang et al. [27] reported that various degrees of mucosal asymmetry and phase irregularities were found in all patients with untreated UVFP.

However, for stroboscopic images, it is challenging to capture an adequate signal in profoundly dysphonic patients with a wide glottic gap. An inverse relationship may exist between vocal dysfunction and stroboscopic images. Stroboscopic images do not represent the true vibratory motion of the vocal folds; instead, they provide composite images of a number of real vibratory cycles. Therefore, good imaging of mucosal wave dynamics requires synchronization of the strobe light with vocal fold vibration [24]. Harries and Morrison [28] assessed the utility of stroboscopy in 100 patients with UVFP. They found that a reliable image of mucosal wave vibration could be obtained only in patients with a small phonatory glottal gap. Another drawback is the lack of agreement in the literature regarding which stroboscopic parameters should be assessed $[13,29,30]$.

Endoscopic and stroboscopic assessments of laryngeal structure and function offer valuable information regarding vocal fold mobility, phonatory glottal closure, the difference in level between vocal folds, and the presence of laryngeal compensation in patients with UVFP. These parameters are closely correlated with the perceptual and subjective voice outcome indicators [31]. Nevertheless, physicians and SLPs should be cautious about using visualization tools as the sole methods on which treatment is directly based.

\section{KQ 2. What is the role of voice assessments in the management of UVFP?}

\section{Recommendation 2}

(A) Voice assessments, including perception, acoustics, aerodynamics, and self-rating questionnaires, are necessary before and after treatment to support the development of a treatment plan, visual feedback, and proper comparison of voice outcomes between treatment modalities for patients with UVFP (strong recommendation, high-quality evidence).

(B) The selection of an assessment tool is based on the patient's capacity to participate effectively and on the examiner's facility with the assessment tool (strong recommendation, low-quality evidence).

a. A perceptual study of the voice, based on grade, roughness, breathiness, asthenic, and strained (GRBAS) scale, is valuable for examining the subjective vocal quality of the patient.

b. Acoustic parameters, including jitter, shimmer, noise- to-harmonic ratio (NHR), and cepstral peak prominence (CPP), provide an objective assessment of the vocal quality of the patient.

c. Aerodynamic parameters, including maximum phonation time (MPT) and mean airflow rate (MFR), are useful for evaluating the glottal insufficiency of patients with UVFP.

d.The voice handicap index (VHI) reflects UVFP patients' perceptions of their own vocal status.

\section{Supporting text}

Voice changes caused by UVFP may have various manifestations. Patients with UVFP typically present with a breathy, leaky voice; however, this is frequently combined with other symptoms, including vocal fatigue, foreign body sensation, diplophonia, and/ or strained voice due to supraglottic compensation [24]. Voice change has long been associated with a diminished self-image. Patients may experience stress, isolation from the community, and depression, all of which influence their social activities and psychological state. Therefore, clinicians and SLPs should evaluate multidimensional aspects of voice, including various vocal features as well as the patients' personal experiences of their condition $[17,24,32,33]$.

Qualification and quantification of the voice changes induced by UVFP enable patients to receive visual feedback on the effects of treatment. If patients have excessive expectations regarding treatment, they may be discouraged after treatment, which may reduce their adherence to the treatment plan. In this situation, laryngologists or SLPs can explain the results of treatment to patients and help modulate their expectations. Measuring voice changes is also important for the treating laryngologists or SLPs. If they have different criteria for satisfaction with UVFP treatment, treatment strategies may differ according to individual preferences. Standardization of treatment outcomes is needed to determine the optimal treatment policy and to establish reasonable clinical practice guidelines for UVFP.

Efforts to establish unified voice outcome indicators have yielded unprecedented results. The assessments of treatment outcomes differ markedly $[34,35]$. Studies dealing with comparisons between various therapies also have not used consistent indicators $[33,35,36]$. This makes it difficult to communicate about the results of research in this field, to make direct comparisons between studies, and to perform meta-analyses; however, this issue may be partially resolved by using a primary set of parameters. The committee set the primary voice assessment parameters using the criteria that these parameters should be widely used, easy to perform, and reflect voice improvement after treatment.

Voice evaluation can be divided into four categories: perceptual, acoustic, aerodynamic, and subjective evaluation. Basic voice evaluation parameters for general voice disorders were 
proposed by the European Laryngological Society (ELS) in 2011 [32]. They recommended assessments of perceptual measures, including grade $(G)$, roughness $(R)$, and breathiness (B) (GRB); acoustics, including jitter, shimmer, fundamental frequency (F0)-range, and softest intensity; aerodynamics with the phonation quotient; and subjective experience, using a questionnaire-based assessment of the VHI [32]. In 2018, the ELS committee published a consensus report on the basic parameters for UVFP. In their study, they analyzed voice outcome data of patients with UVFP using the authors' databases. Based on their data, they suggested that the VHI was preferable [33]. They also suggested that it should be mandatory to use perceptual analysis with the GRB scale, that it is preferable to conduct breathiness and aerodynamic studies using at least the MPT, and that the use of acoustic analysis should be considered optional.

In their systematic review, Desuter et al. [34] reported that 11 voice outcome parameters accounted for $80 \%$ of all parameters used in UVFP studies evaluating the efficacy of surgical intervention. These parameters included MPT, jitter, shimmer, the NHR, mean airflow, F0, informal perceptual scales, the GRBAS scale, mean subglottic pressure, and the VHI-30. Of these parameters, MPT most commonly showed significant improvements $(90 \%)$ after surgical intervention, followed by mean airflow $(86 \%)$, the GRBAS scale $(85 \%)$, NHR $(80 \%)$, jitter $(74 \%)$, shimmer $(68 \%)$, the VHI (64\%), mean subglottic pressure $(45 \%)$, and F0 (33\%). Another systematic review by Baylor et al. [29] evaluated the efficacy of voice therapy and found that MPT, the MFR, jitter, shimmer, informal perceptual scales, F0, NHR, the F0 range, and the VHI were frequently used as parameters in UVFP studies. They reported results in accordance with those of Desuter et al. [34]. The VHI (100\%) was the most commonly used parameter (61\%), followed by mean air flow (61\%), jitter (54\%), NHR (54\%), MPT (53\%), shimmer (46\%), informal perceptual scales (41\%), the F0 range (35\%), and F0 (19\%) [29]. The major limitation of perceptual scales is the inconsistency of values between raters. Jitter is calculated based on F0 and cannot be measured in patients with aperiodic acoustic signals. Nonetheless, these findings imply that these parameters are accessible, and their use facilitates the interpretation of related results between research studies.

Recently, cepstral analysis has been found to be useful in UVFP patients. Cepstral parameters, including CPP, which is produced by the Fourier transformation of a spectrum, provide an indication of the degree of glottal gap. CPP is detected in both normal and breathy voices, but is more prominent in periodic voices. When the voice becomes breathy, $\mathrm{CPP}$ values are lowered [37-39].

Taken together, the committee suggests that perceptual measures of the voice based on the GRBAS scale; acoustics with jitter, shimmer, NHR, and CPP; aerodynamics with the MPT and MFR; and the VHI as a subjective questionnaire should be employed in assessments. The committee does not set any priorities between these different voice parameters. Rather, a basic set of parameters may be tailored according to the patient's capacity to participate effectively and the examiner's facility with the assessment tools.

\section{KQ 3. What is the role of imaging studies in the diagnosis of UVFP?}

\section{Recommendation 3}

Neck CT or magnetic resonance imaging (MRI) encompassing an area from the skull base to the thoracic inlet/arch of the aorta is recommended to identify the underlying cause of the pathology for patients with unexplained UVFP (strong recommendation, high-quality evidence).

\section{Supporting text}

Although an evidence-based clinical practice guideline has been published on the evaluation of certain causes of hoarseness, variations in the use of imaging studies in the diagnosis of UVFP remain. In a systemic review of seven published studies (1,308 patients with UVFP), Macgregor et al. [40] found that surgical trauma and neoplastic lesions (predominantly lung and thyroid cancer) accounted for $22 \%$ of all cases. However, in recent years, the etiology of UVFP has changed, with up to $37 \%$ of cases being secondary to surgical procedures [41].

No articles were found in the systematic review dealing with the diagnostic yield of imaging studies prior to laryngeal examination. However, further imaging studies are generally recommended after laryngoscopy reveals UVFP and if surgery can be ruled out as the cause of the paralysis [42]. Imaging is not usually required if the onset of UVFP coincides with surgery on the appropriate side of the neck or to the mediastinum in left-sided UVFP, since surgical damage to the nerve cannot be detected with current imaging techniques. A retrospective study has suggested that a thorough radiological investigation can help to improve the diagnostic rate by reducing the number of "idiopathic" cases and can guide appropriate treatment [43].

When clinicians suspect a lesion along the RLN, imaging studies are also indicated. Unexplained UVFP found on laryngoscopy warrants imaging from the skull base to the thoracic inlet/ arch of the aorta. Including these anatomical areas allows for evaluation of the entire path of the RLN as it loops around the arch of the aorta on the left side. On the right side, imaging will show any lesions in the lung apex along the course of the right RLN as it loops around the subclavian artery.

A previous study showed that a complete radiographic workup improved diagnostic rates [43], but controversy remains regarding whether CT or MRI is better for evaluating the RLN $[40,44]$. Lesions at the skull base and brain are best evaluated using MRI of the brain and brain stem with gadolinium enhancement. For patients presenting with additional lower cranial 
nerve palsy, the skull base, particularly the jugular foramen (cranial nerves IX, X, and XI), should be covered in the imaging study [42].

\section{KQ 4. What is the role of electromyography in the management} of UVFP?

\section{Recommendation 4}

(A) Laryngeal electromyography (LEMG) is useful to differentiate VFP from mechanical causes, including arytenoid fixation or dislocation for patients with unilateral vocal fold immobility (strong recommendation, high-quality evidence).

(B) LEMG provides prognostic information about patients' recovery of neural function (strong recommendation, high-quality evidence).

\section{Supporting text}

In 1944, Weddel first introduced LEMG and suggested that this technique may have diagnostic and prognostic value for UVFP; since then, the technique has advanced and its clinical applications have expanded $[45,46]$. When immobility of a vocal fold is observed unilaterally, the most frequent cause is laryngeal paralysis, but other possible causes also have to be considered. Although visual and voice assessments are widely used for the management of UVFP (see KQ 1 and 2), these tools do not differentiate well between neurologic disorders and mechanical disorders. For such cases, LEMG can be useful for confirming that the mobility disorder has a neurologic basis and for establishing a management plan [47]. Heman-Ackah and Barr [48] revealed that, based on LEMG, the medical treatment plan was changed in 10 of 37 patients $(27.0 \%)$ and the treatment course was confirmed in 12 of 37 patients (32.4\%), whereas there was no change in the plan initially determined by a visual assessment in 15 of 37 patients (40.0\%). Focquet et al. [49] evaluated 61 patients with UVFP and found that LEMG could successfully differentiate a neurologic cause in $85 \%$.

Under normal neuromuscular conditions, no spontaneous activity should be present during the resting state. During voluntary contraction, a reduced number and recruitment of motor unit active potentials (MUAPs; $<80 \%$ compared to the normal side) and the presence of synkinesis reflect neural and muscular degeneration [50,51]. The absence of spontaneous activity, normal biphasic MUAPs or polyphasic reinnervation potential, and normal recruitment ( $>80 \%$ compared to the normal side) are associated with a good prognosis. Favorable signs on LEMG can guide clinicians to pursue a period of observation or to use vocal fold injections with temporary materials that dissipate in 2-3 months $[52,53]$. The presence of spontaneous activity (e.g., fibrillation potential, myotonic discharge, fasciculations, positive sharp waves, complex repetitive potentials) and synkinesis or decreased MUAP recruitment indicates a poor prognosis. If LEMG reveals a poor prognosis, permanent surgical treatment, such as arytenoid adduction (AA) or vocal fold injection with permanent material, is recommended [54]. In a meta-analysis reporting LEMG results and clinical outcomes from 10 studies (503 patients), a positive-predictive value (proportion of poor recovery when LEMG predicted a poor prognosis) of $90.9 \%$ and a negative-predictive value (proportion of good recovery when LEMG predicted a good prognosis) of $55.6 \%$ were found [55].

It remains unclear how soon LEMG results become reliable after the onset of VFP. Pathologic spontaneous activity indicating axonal degeneration does not appear until 10-14 days after the initial injury [56]. Although studies vary in their initial time frame to LEMG (earliest reported time period: 2 weeks), most suggest performing LEMG within 6 weeks, and regard LEMG testing after 6 months as inaccurate $[47,55]$.

\section{B. Spontaneous recovery}

KQ 5. What is the appropriate period in which to expect spontaneous recovery of a paralyzed vocal fold?

\section{Recommendation 5}

Spontaneous recovery of vocal fold mobility can occur within 6-12 months from the onset of UVFP (strong recommendation, moderate-quality evidence).

\section{Supporting text}

Most patients with UVFP, if there is no definite evidence of transection of the RLN, ask about the time to recovery, as well as the prognosis regarding their vocal fold movement. This is also important for the treating physicians. When treating patients with UVFP, the prognosis of neural function recovery is critical for deciding the choice of treatment. If UVFP is not likely to recover, permanent procedures may be offered to address the patient's symptoms without disturbing the patient by performing multiple procedures with transient effects. However, if patients expect restoration of vocal fold movement, permanent procedures could interfere with the normal vibratory function of the vocal fold, as these procedures also involve modification of the patient's laryngeal structure. Prognostic prediction may be facilitated by LEMG findings. Denervation potentials suggesting axonal injury without recovery potential indicate a poor prognosis for neural recovery (see KQ 4). However, LEMG is not readily accessible at most private and low-volume hospitals, meaning that physicians still use clinical information to assess the likelihood of recovery. It appears that most clinicians make a decision about the likelihood of recovery a long time after injury.

Neural injuries are classified as nerve conduction blocks and axonal injuries [57,58]. A nerve conduction block, also called neurapraxia, involves a myelin injury with an intact axon. In 
such cases, neural function usually recovers within 8 weeks, along with regeneration of Schwann cells. However, when the axon is injured, which is known as axonotmesis, the recovery is poor. The severity of axonal injuries varies, as they may result in neuronal death or in re-innervation of the target cell; this variation makes patients' recovery unpredictable. Unfortunately, grossly intact nerve continuity does not reflect integrity of the intact axon [59-61].

In 2008, Sulica [62] performed an excellent meta-analysis on the natural history of idiopathic UVFP, and found that spontaneous recovery of vocal fold mobility occurred within 6 to 12 months from onset of UVFP. Another study by Husain et al. [63] reviewed the medical records of all patients with idiopathic UVFP over a 10 -year period. Demographic and clinical information, including onset of disease and recovery of vocal fold movement, were analyzed. Thirty-eight of the 55 patients $(69 \%)$ recovered vocal fold movement, and this occurred within 6 months of onset in two-thirds of patients. The declining probability of recovery over time leads us to consider the value of laryngeal framework surgery (LFS) after 6 months in patients with no precipitating cause [63]. Mau et al. [64] reviewed 727 cases of UVFP in order to determine the time to voice recovery, and reported that $86 \%$ of patients with recoverable UVFP recovered within 6 months, with $96 \%$ recovering within 9 months. The authors concluded that waiting 12 months for spontaneous recovery is probably too conservative, and recommended that it would be reasonable to pursue permanent management after 9 months [64]. Taken together, in most cases, recovery may happen within 6 months after injury, while a minority of cases recover between 6 and 12 months.

\section{Medical treatment}

KQ 6. Does systemic steroid treatment improve the natural course of UVFP?

\section{Recommendation 6}

Routine prescription of systemic steroids is not recommended for the treatment of UVFP because these drugs may cause adverse effects, while there is a lack of evidence for their benefit in the recovery of neural function (strong recommendation, low-quality evidence).

\section{Supporting text}

UVFP may result from iatrogenic or traumatic causes and from neoplastic or systemic inflammatory diseases (See KQ3). Traditional support for the use of systemic steroids might be due to training in otolaryngology [65]. The efficacy of systemic steroids for Bell's palsy (idiopathic facial palsy) and sudden hearing loss is well documented, as systemic steroids can reduce or completely alleviate the symptoms of patients with these conditions $[66,67]$. Theoretically, systemic steroids may counteract inflammation of the innervating vagus nerve and facilitate recovery to neuropraxia, thereby allowing vocal fold mucosal movement to recover to its normal state. Oral steroids are prescribed for VFP by general practitioners $(2.4 \%)$ and laryngologists $(5 \%)$ in the United States [65]. At the 2017 KSLPL fall meeting, a survey was conducted regarding systemic steroid use for UVFP, and three of 29 laryngologists $(10.1 \%)$ supported the use of systemic steroids (oral or parenteral) for UVFP (unpublished data). Although this may be fairly common in practice, no studies have provided evidence of the benefit of steroids for promotion of recovery from VFP. Prospective studies on the use of steroids for relief of hoarseness in UVFP are also lacking, except for special conditions, as discussed below.

Although RCTs should be conducted to evaluate the use of steroids for UVFP, a few studies have assessed the benefits of single-dose corticosteroid administration in a perioperative setting to prevent voice changes after thyroid surgery. In a prospective, case-control study of 295 patients by Wang et al. [68], the effect of corticosteroid use on recovery of the RLN after thyroid surgery was assessed. The rates of temporary and permanent VFP were $5.7 \%$ (11 of 194) and $0.52 \%$ ( 1 of 194), respectively, and $6.9 \%$ (12 of 173) and $0.58 \%$ ( 1 of 173), respectively, in the groups with and without corticosteroids. Although this difference did not reach statistical significance, among the 23 patients who recovered from VFP, the mean time to recovery was shorter for patients who received intraoperative steroids ( 28.6 vs. 40.5 days, $P=0.045$ ). Despite the weak statistical significance, the difference of 8 days is of uncertain clinical importance. The authors stated that no patients reported complications associated with the use of corticosteroids [68]. However, a recent meta-analysis revealed that perioperative steroid use does not appear to reduce the risk of VFP and short-term voice disturbances after thyroidectomy [69]. Given the known potential adverse effects of steroids, prospective studies examining the benefits relative to placebo are warranted.

Some case series of VFP associated with Ramsay-Hunt syndrome or idiopathic fibrosing mediastinitis, or autoimmune disorders, such as sarcoidosis, systemic lupus erythematosus, and relapsing polychondritis, showed the effectiveness of steroids for dysphonia, although with very low-quality evidence [70-73]. However, the effects of steroids on the recovery of UVFP in these case series are still unclear. Further detailed assessments of the potential adverse effects of steroids are necessary to allow a risk versus benefit determination.

\section{Surgical treatment \\ KQ 7. What should be considered when selecting injection ma- terials in UVFP?}

\section{Recommendation 7}

The properties of the injection materials, as well as the duration and cause of UVFP, should be considered when choos- 
ing a material for injection. Temporary or short-duration materials are used when spontaneous recovery of vocal fold mobility is expected (strong recommendation, moderatequality evidence).

\section{Supporting text}

Numerous materials have been introduced for injection laryngoplasty (IL) in UVFP patients since the early 1990s. However, earlier injectable materials such as paraffin and Teflon have gradually been phased out given the evidence of various inflammatory and foreign body reactions in response to those materials, as well as the high extrusion rates [74]. The requirements for injection materials include minimal tissue response, absence of oncogenicity, non-absorbability, and absence of migration [75,76].

Injection materials are typically described according to their origin as synthetic, autograft, xenograft, and homograft. However, for clinical purposes, it is more useful to classify injection materials according to their duration as temporary and longlasting. The viscoelastic properties and biocompatibility of materials determine their duration. Hyaluronic acid (HA), collagen, and carboxymethylcellulose (CMC) are considered to be temporary materials. Long-acting materials include calcium hydroxyapatite (CaHA), fat, and polymethylmethacrylate (PMMA) microspheres in bovine collagen. Clinicians should consider the properties of the injection materials and the cause of UVFP when choosing a material for IL. Temporary material is used in cases of UVFP with no apparent cause. The main purpose of temporary vocal fold injection is to restore laryngeal function during the process of neural recovery of the paralyzed vocal fold. IL with temporary materials may be performed as a trial augmentation to establish whether permanent vocal fold augmentation will be successful in the future. A permanent or longlasting material is used in cases of irreversible UVFP due to apparent nerve injury.

In Korea, for augmentation in UVFP cases with glottal incompetence, HA and collagen are used as temporary materials, and CaHA and PMMA microspheres in bovine collagen are commonly used as long-lasting materials (unpublished data, 2017 KSLPL fall meeting survey). These materials are highly biocompatible, biologically stable, and have been reported to yield good postoperative voice function. Below, we focus on the materials commonly used in Korea. The various injection materials used for augmentation of UVFP are summarized in Table 4.

\section{Hyaluronic acid}

HA, the most common extracellular matrix glycosaminoglycan found in various human tissues, including the lamina propria of the vocal fold, promotes tissue repair and regeneration in vocal cords by providing synthetic building blocks for the extracellular matrix. In a rabbit vocal fold model, it was shown that HA has similar viscoelastic properties to vocal fold tissue, and may be the best candidate for the replacement of the lamina propria [77]. It has very low tissue reactivity, but delayed hypersensitivity has been reported after injection in the facial area [78]. The duration of HA after vocal fold injection is believed to be about 6 months; however, experience shows that its clinical benefit

Table 4. Classification of injection materials

\begin{tabular}{|c|c|c|c|c|c|c|}
\hline Injection materials & Product name & Category & Composition & Clinical use & Duration & Comment \\
\hline Hyaluronic acid & $\begin{array}{l}\text { Restylane } \\
\text { Rofilan } \\
\text { Neuramis }\end{array}$ & Xenograft & $\begin{array}{l}\text { Extracellular matrix } \\
\text { glycosaminoglycan }\end{array}$ & Temporary & $\begin{array}{l}\text { 4-6 Months, but clinical } \\
\text { benefit may last up to } \\
12 \text { months }\end{array}$ & Most commonly used \\
\hline \multirow[t]{3}{*}{ Collagen } & Zyplast & Xenograft & Bovine-based collagen & Temporary & 3-4 Months & $\begin{array}{l}\text { Possible adverse immunogenic } \\
\text { reactions } \\
\text { Requires skin test prior to use }\end{array}$ \\
\hline & Cymetra & Homograft & $\begin{array}{l}\text { Micronized cadaveric } \\
\text { dermis }\end{array}$ & Temporary & $\begin{array}{l}\text { 3-4 Months, but clinical } \\
\text { benefit may last up to } \\
12 \text { months }\end{array}$ & Does not require a skin test \\
\hline & $\begin{array}{l}\text { Cosmoderm } \\
\text { Cosmoplast }\end{array}$ & Homograft & $\begin{array}{l}\text { Genetically engineered } \\
\text { human collagen }\end{array}$ & Temporary & 3-4 Months & $\begin{array}{l}\text { Does not require a skin test } \\
\text { Limited evidence for UVFP }\end{array}$ \\
\hline $\mathrm{CaHA}$ & Radiesse & Synthetic & $\begin{array}{l}\text { CaHA with CMC } \\
\text { carrier gel }\end{array}$ & Permanent & $\begin{array}{l}18 \text { Months, may last up to } \\
\text { more than } 2 \text { years }\end{array}$ & FDA-approved \\
\hline $\begin{array}{l}\text { PMMA in bovine } \\
\text { collagen }\end{array}$ & $\begin{array}{l}\text { Artecoll } \\
\text { Artefill }\end{array}$ & $\begin{array}{l}\text { Xenograft+ } \\
\text { synthetic }\end{array}$ & $\begin{array}{l}\text { PMMA in bovine } \\
\text { collagen }\end{array}$ & Permanent & More than 2 years & Requires a skin test prior use \\
\hline Fat & & Autograft & Autologous fat & Permanent & $\begin{array}{l}\text { Variable duration due to } \\
\text { absorption }\end{array}$ & $\begin{array}{l}\text { Prolonged harvest time } \\
\text { Unpredictable fat survival }\end{array}$ \\
\hline $\mathrm{CMC}$ & $\begin{array}{l}\text { Radiesse } \\
\text { Voice Gel }\end{array}$ & Synthetic & $\mathrm{CMC}$ & Temporary & 2-3 Months & $\begin{array}{l}\text { Limited use due to short-lasting } \\
\text { effects } \\
\text { FDA-approved }\end{array}$ \\
\hline
\end{tabular}

UVFP, unilateral vocal fold paralysis; CaHA, calcium hydroxyapatite; CMC, carboxymethylcellulose; FDA, Food and Drug Administration; PMMA, polymethylmethacrylate. 
may last up to 12 months $[79,80]$. Commercially available HA formulations include Restylane, Hyalaform, Reviderm, and Rofilan; however, none of these are currently Food and Drug Administration (FDA)-approved for vocal fold injection.

\section{Collagen}

There are currently two sources of collagen used in IL: bovineand human-based collagen. Bovine-based collagen (Zyplast) is thought to last 3-4 months [81]. Concerns have been raised about possible adverse immunogenic reactions to this substance, although the risk is very low (3.5\%) [82]. Extensive clinical experiences with this type of collagen as a dermal filler have shown late local and systemic adverse reactions. Patients with a history of autoimmune disease are expected to have a higher incidence of allergic reactions, and should not be injected [82]. The FDA requires skin tests prior to use of this substance for injection [83]. This has led to the development of other biologic materials for use. Human-based collagen products include a micronized acellular compound from cadaveric dermal tissue (Cymetra) and genetically engineered human collagen (Cosmoderm, Cosmoplast). These have demonstrated good results in terms of glottic closure, voice quality, and voice-related quality of life [84]. Owing to its good safety profile, multiple repeated injections are usually nonproblematic. However, over-injection is required to account for the high likelihood of resorption. Collagen-based products have been shown to last for an average of 2-3 months, but radiologic evidence has shown that their effects can last for more than 1 year. Tan and Woo [85] conducted a retrospective study with 83 patients, of whom $54 \%$ showed a persistent duration over 12 months. Only limited experience with genetically engineered human collagen products for augmentation as treatment for UVFP has been accumulated. The FDA does not require skin testing for human collagen materials, but these substances are currently not FDA-approved for vocal fold injection [83].

\section{Calcium hydroxyapatite}

CaHA, also known as Radiesse Voice, consists of microspheres of CaHA suspended in a CMC carrier gel, and is currently the only FDA-approved substance for long-lasting vocal fold injections. In a canine vocal fold model, CaHA injection resulted in enough medialization to regain glottal closure without resorption of microspheres throughout the 12-month follow-up period. However, because of resorption of CMC, slight over-augmentation may be needed [86]. Rosen et al. [87] prospectively evaluated the effectiveness of CaHA up to the 12-month time-point in 63 patients. At 12 months, $81 \%$ of patients subjectively reported at least moderate improvement in their voice. Carroll and Rosen [88] reported the long-term results of CaHA in 91 patients and demonstrated that CaHA may last for 2-3 years, with an average clinical benefit of 18.6 months. Although CaHA is a naturally occurring mineral in the human body and should therefore be biocompatible, several case reports have described giant-cell foreign body reaction or pulmonary embolism related to CaHA $[83,89,90]$.

\section{Polymethyl methacrylate in bovine collagen}

Homogenous PMMA microspheres (20\% by volume) evenly suspended in a solution of partly denatured bovine collagen $(80 \%$ by volume; Artecoll) serves as a vehicle for deep dermal implantation. After injection, the collagen carrier is rapidly broken down by the body within 1-3 months and completely replaced by the body's own collagen at a similar proportion, ensuring a steady augmentation result. The complication rates are relatively low. Min et al. [91] reported long-term follow-up results of Artecoll in 98 UVFP patients. They demonstrated continuous subjective and objective voice improvements lasting more than 2 years, without adverse effects.

\section{KQ 8. Which techniques are preferred for injection laryngoplas-} ty?

\section{Recommendation 8}

(A) No single technique shows superior results to other approaches with regard to voice outcomes (strong recommendation, low-quality evidence).

(B) The preference of the patient and the experience of the laryngologist, along with the availability of resources, should be taken into account when deciding on the technique for IL (strong recommendation, moderate-quality evidence).

\section{Supporting text}

IL, which has become increasingly popular for the management of UVFP, is conventionally performed in the operating room utilizing microlaryngoscopy under general anesthesia [92]. However, improved endoscopic technology, particularly distal chip endoscopes, have made early interventions possible in awake patients [92-94]. The advantages of office-based IL include markedly decreased cost, avoidance of the risks of general anesthesia, and the ability to titrate the amount of delivered injectables through real-time feedback from awake patients for optimized voice outcomes [95].

Consequently, laryngologists from various regions have developed and fostered a range of approaches. However, no single technique shows superior results to other approaches in terms of voice outcomes. The choice of injection technique depends on the preference of the patient and the experience of the laryngologist, along with resource availability. The transcutaneous cricothyroid membrane submucosal approach is a long-standing, commonly used technique [96]. However, this approach has a substantial learning curve due to the difficulty in precisely localizing the injection needle [97]. The transcutaneous thyrohyoid 
membrane approach, contralateral paramedian cricothyroid membrane approach, and transnasal endoscopic approach utilizing the "chip-tip" endoscope have been proposed as alternatives that enable better localization of the needle tip $[76,97,98]$. However, these approaches involve violation of the airway mucosa, which poses a potential risk of bleeding or patient discomfort during the procedure. The transcutaneous transthyroid cartilage approach has also been developed as an alternative with the advantage of relative anatomical simplicity for submucosally locating the needle to reach the paraglottic space, as compared to the cricothyroid membrane approach [99]. However, ossification of the thyroid cartilage limits this approach in elderly patients, who constitute the majority of UVFP patients.

\section{KQ 9. What is the best timing for injection laryngoplasty?}

\section{Recommendation 9}

IL can be applied at any stage of UVFP. Early and active intervention with temporary injection materials is recommended to prevent lung complications and to ensure the quality of life of a patient with high vocal demands (strong recommendation, moderate-quality evidence).

\section{Supporting text}

One of the most frequent questions of laryngologists regarding the treatment of UVFP patients is "When is the best time to treat them?" The classic clinical decision has been to wait for at least 6-12 months before conducting permanent medialization treatment in UVFP patients (see KQ 5). However, due to the development of various biomaterials for injection with differing durations of efficacy, higher patient expectations, and improved injection techniques in the outpatient setting, the wait-and-see policy has recently been challenged [95]. The etiology of UVFP is also changing, with a major proportion $(37 \%-60 \%)$ of cases being secondary to surgical trauma [33,41]. Because patients with UVFP are frequently elderly, with multiple comorbidities, and surgery sometimes results in injuries to multiple cranial nerves, the sequelae of UVFP can be serious, with symptoms including not only hoarseness or dysphonia, but also dysphagia, aspiration, and poor cough production, which may contribute to a poor postoperative quality of life and even impact the survival of patients with UVFP. Consequently, the concept of early postoperative interventions has gained increasing acceptance. Early IL could help patients to return to work and the community, and thereby reduce the risk of aspiration and dysphagia $[95,100]$. A more detailed discussion is provided in the section on KQ 16.

Although IL with transient material does not facilitate nerve regeneration, several studies have reported the long-term clinical benefits of early IL. A meta-analysis showed that injection with transient materials yielded clinical benefits lasting for up to
12 months and reduced the risk of LFS [101]. In that analysis, the overall pooled relative risk of medialization thyroplasty (MT) in patients undergoing early injection was 0.25 (95\% confidence interval, 0.14-0.45) compared to those undergoing late or no injection. A large glottal gap on presentation may a risk factor for failure of IL, requiring LFS. However, even in those situations, early IL has been shown to lower the risk of subsequent framework surgery.

\section{KQ 10. What is the optimal follow-up interval after injection la- ryngoplasty?}

\section{Recommendation 10}

Scheduling the first follow-up visit within 1 week to 1 month after injection is reasonable in order to detect short-term complications and to evaluate the results. Subsequent followup visits at 3-6 months and 1 year later would be appropriate to detect long-term effects (weak recommendation, lowquality evidence).

\section{Supporting text}

After IL is performed, the surgeon should document procedurerelated complications, voice outcomes, and their maintenance during the follow-up period (see KQ 1, 2). Surgeons schedule follow-up visits with patients at various intervals according to their own rationale and preferences. However, too short a follow-up interval may be inconvenient for the patient and increase the patient's medical costs, while too long an interval may miss important complications that can reverse treatment outcomes. An optimal follow-up interval is also important for proper comparisons between studies, because most injection materials are probably transient and are absorbed over time (see KQ 7). Therefore, an optimal follow-up interval should be identified.

Unfortunately, there is no consensus on standard follow-up strategies after IL. Several cases of complications of percutaneous IL have been reported, although these are very rare. The complication rate of IL has been reported to be $2 \%-3 \%[88,92$ 94,102-104]. Post-injection complications included rapid absorption of the injected materials (defined as the need to perform a re-injection within 4 weeks of the procedure), failure of the procedure, malposition of the injection (e.g., injection of the superficial lamina propria), and migration of the injected material [105]. Other acute complications may include post-injection hematoma, infection, edema, and hypersensitivity reaction causing dyspnea [106,107]. Most acute complications occur within 1 week. Immediately after IL, the voice sounds pressed, which gradually improves with the even distribution of injection materials within 1 week [92].Therefore, many surgeons have adopted a first post-injection follow-up interval within 1 month. However, if IL is performed to prevent aspiration, the first follow-up in- 
terval should be shorter, within 1-2 weeks. The follow-up interval can also be affected by the injection material used, the method of injection, the size of the injection needle bore, and neural function recovery potential.

Maintenance of injection materials varies with their biomechanical profiles. The temporary injectables currently in use, such as collagen products, micronized dermal matrix, and HA, are traditionally known to be resorbed within approximately 3-6 months, but recent studies of IL using temporary injection materials have reported that the augmentation effect may last for up to 12 months [79,80,101,102,108-113]. When using fat or $\mathrm{CaHA}$ as an injection material to treat permanent causes of glottic insufficiency, clinical efficacy is maintained for over 1 year [88,114-116]. Temporary IL is preferred for cases of UVFP with no apparent cause (i.e., where there is a possibility of recovery of neural function). Through several studies of IL in patients with recoverable UVFP, it is reasonable to wait for a period of 6-12 months to see whether recovery takes place (see KQ $5)$. For those reasons, post-injection follow-up should occur at 3-6 months, and then at 12 months. Data from a recent metaanalysis showed that the most commonly reported interval for postoperative voice outcome analysis was 6 months (60 of 72), followed by 1 month (50 of 72), 3 months (49 of 72), and 1 year (48 of 72) [34].

\section{KQ 11. Is immediate voice rest after injection laryngoplasty necessary?}

\section{Recommendation 11}

There is no evidence regarding the benefit of voice rest after IL. However, many surgeons recommend a voice rest of 1-2 days after injection (weak recommendation, low-quality evidence).

\section{Supporting text}

Voice rest after phonomicrosurgery is commonly recommended for mucosal healing, and a majority of laryngologists implement 7 days of complete voice rest. However, there is no consensus regarding the necessity of voice rest after IL, and only a few reports have specified the protocols of voice rest used after injection.

After injection, the durability of beneficial outcomes can be affected by the viscosity of the injected materials. Due to migration or early resorption, adverse effects can occur. Based on the belief that voice rest after injection helps to avoid migration and absorption, many surgeons prefer to advise voice rest after IL. CaHA is commonly used for permanent injection, but its viscosity is similar to that of water. In a previous study, 6 days of voice rest was prescribed after vocal fold injection to help optimize implant stability [117]. In another study on IL using CaHA, patients were instructed to rest their voice overnight and to use oral analgesics if necessary [115]. In cases where Cymetra was used, patients were advised to use a soft voice for 2 days, after which there were no voice restrictions [118]. Another study of procedures using HA recommended 2 days of voice rest, although patients with scars were prescribed strict vocal rest for 8 days [119]. In cases of fat injection, voice rest for 48 hours was recommended [116].

In the 2017 KSLPL fall meeting survey, a questionnaire was administered to 14 expert laryngologists; in terms of the necessity of voice rest, half of these experts advised 24 hours of voice rest, and four recommended 3-4 days of voice rest after injection. Only two did not recommend voice rest at all. Thus, many surgeons prefer 1 or 2 days of voice rest after injection, even though there is a lack of evidence regarding the benefit of voice rest. However, if the injection materials are unevenly distributed and the vocal fold displays an irregular shape, active throat clearing or coughing may help to distribute the material more evenly [92].

\section{KQ 12. When is injection laryngoplasty preferred to medializa- tion thyroplasty in cases of permanent UVFP?}

\section{Recommendation 12}

IL is preferred for patients with a short life expectancy or significant comorbidities, and for those who do not want to sustain a visible neck scar (weak recommendation, low-quality evidence).

\section{Supporting text}

If UVFP is considered to be permanent, patients can be treated by either IL or LFS. The effect of IL is not permanent in most cases, and multiple injections may be required [120]. In previous decades, LFS has been considered the "gold standard" of treatment for permanent UVFP, and it still represents an excellent option for many patients (see KQ 13).

As discussed in the KQ 9 section, advances in injection techniques and the development of distal chip endoscopes have made IL possible in awake patients [93,94]. With the help of a smallgauge needle $(26 \mathrm{G})$ to inject materials and a high-definition endoscope, the clinician is able to deliver injection materials to the paraglottic area or thyroarytenoid muscle with less pain and better precision. With advances in injection materials and methods, the results of IL have become comparable to those of LFS. A meta-analysis comparing IL using CaHA versus MT using silicone showed comparable voice improvement within 1 year in terms of the VHI and MPT [121]. Furthermore, in a systematic review of relative outcomes of interventions for UVFP, IL and MT showed no significant differences in postoperative improvement assessed using objective (acoustic and aerodynamic outcomes; MPT, jitter, shimmer, NHR, etc.), subjective (VHI, Consensus Auditory-Perceptual Evaluation of Voice [CAPE-V] etc.), 
and laryngoscopic outcomes [122]. Some studies have reported that IL with CaHA and fat showed better outcomes than MT in terms of NHR, MPT, and acoustic variables [123-125].

The other advantages of IL are that it is technically easier and requires a short procedure time. MT is usually performed in sedated patients under local anesthesia. AA procedures are technically more demanding, requiring more surgical experience $[104,126]$. Both procedures leave a visible neck scar. Transoral $\mathrm{AA}$, which has a less visible neck scar, has been attempted; however, this procedure requires general anesthesia $[127,128]$. In contrast, in-office awake IL can be performed quickly and easily, and does not necessarily produce a neck scar. Patients tolerate the procedure well and are typically satisfied with the results [94]. The approach is useful for patients with a history of previous head and neck surgery, and in those who do not want to sustain a visible neck scar.

Complications after LFS are affected by the surgeon's experience, with complication rates up to $19 \%$ reported in the literature $[126,129]$. The reported complications include surgical site infection, hematoma, laryngeal edema, dysphagia, implant extrusion, and airway compromise. These complications are more frequent than in IL, which is reported to have a complication rate of around $2 \%-3 \%$ [88,92-94,102-104].

Patients with permanent UVFP may not want to undergo multiple injection procedures [120]. However, patients who have a short life expectancy and multiple comorbidities are not suitable for enduring an hour of general anesthesia and sedation. IL is particularly helpful in this subset of patients for restoring voice and swallowing functions $[103,130]$.

\section{KQ 13. When is AA combined with medialization thyroplasty preferable to medialization thyroplasty only?}

\section{Recommendation 13}

hen a large posterior glottic gap and/or a level difference is present, the addition of AA to MT may be beneficial for improved voice outcomes (weak recommendation, low-quality evidence).

\section{Supporting text}

Both MT and AA offer a permanent solution for treating UVFP by reducing the glottal gap [131]. MT achieves this goal by inserting autologous or synthetic material through the window of the thyroid cartilage [132]. AA is designed to address a wide posterior glottic gap and vertical height discrepancy. This procedure includes making a suture on the muscular process, and then placing a secure knot anteriorly in the apex of the thyroid cartilage. By rotating the arytenoid cartilage, the surgeon can control the position of the vocal process and the asymmetry between the level of the two vocal folds [133]. Currently, AA is generally performed as an adjunct to MT, when the latter alone fails to achieve optimal outcomes.

There is an ongoing debate about the preferred indications for adding AA to MT. Laryngologists' opinions vary from "never" to "always" $[122,134,135]$. In separately performed systematic reviews by Chester and Stewart [134] and Siu et al. [122] although AA combined with MT was found to be an effective option for treating permanent UVFP, statistically significant differences were not found when MT was compared to AA in terms of postoperative voice outcome indicators. Li et al. [136] found no significant differences between MT alone or combined with AA in 45 patients with UVFP, according to postoperative stroboscopic findings. However, ironically, their results may provide evidence justifying the use of AA in combination with MT.

In the study by Li et al. [136], patients undergoing AA with MT had wider glottic gaps and larger vertical height differences than those who underwent MT alone. Mortensen et al. [137] showed that patients who underwent AA with MT had worse preoperative voice function and better postoperative voice function than those who underwent MT alone.

Chang et al. [138] showed that a normalized anterior gap was achieved after both MT alone and AA with MT, whereas AA with MT yielded better results in terms of normalization of the posterior gap. These results imply that AA is necessary to achieve the desired voice outcome in patients with a wide gap and a marked height difference.

KQ 14. If RLN damage is identified during the operation, can immediate re-innervation procedures be effective for improving voice outcomes?

\section{Recommendation 14}

Intraoperative RLN re-innervation, including primary reanastomosis or ansa cervicalis-to-RLN neurorrhaphy, should be considered if direct laryngeal nerve injury occurs during the surgical procedure (strong recommendation, moderatequality evidence).

\section{Supporting text}

Primary intraoperative RLN reinnervation is theoretically an ideal approach for improving voice due to UVFP. Intraoperative RLN reinnervation, in which neurorrhaphy is performed between the distal RLN and intact proximal RLN (primary reanastomosis or greater auricular nerve [GAN] free grafts) or other intact nerves, including the ansa cervicalis (ansa-RLN) and hypoglossal nerve (hypoglossal-RLN) during the surgical procedure, may prevent progressive loss of thyroarytenoid muscle tension and bulk [139]. By using this procedure at the time of surgery, subsequent medialization procedures may be avoided. This procedure also does not require implantation of any foreign body material, and has no risk of potential airway compromise [140-144]. However, intraoperative RLN re-innervation may 
take about 3-6 months to become effective; thus, the voice initially worsens after the procedure due to denervation. From a long-term viewpoint, reinnervation procedures show favorable voice outcomes.

In a systematic review, Aynehchi et al. [145] described that ansa-RLN neurorrhaphy showed the greatest improvement of the glottal gap, as compared with other reinnervation techniques. Lee and Park [142] reported the efficacy of intraoperative re-innervation in 19 thyroid surgery patients. Based on their results, patients undergoing ansa-RLN reinnervation or direct re-anastomosis of the RLN showed statistically significant improvements after 12 months, and the improvements remained stable until 36 months after surgery, with no deterioration of voice parameters. After 36 months, the RLN reinnervation group showed better voice outcomes than those who received IL [142].

Among the different reinnervation techniques, ansa-RLN anastomosis may be preferable in most cases. During thyroid surgery, primary re-anastomosis of the RLN may be limited, except in cases of accidental resection with a preoperatively intact RLN. In most cases of extensive thyroid tumors with invasion of the RLN, the RLN usually demonstrates marked involvement. If it is possible to use a free nerve graft, anastomosis with the GAN or ansa cervicalis can be a good option. However, free nerve grafting requires identification of the intact proximal RLN stumps. During neck or thoracic surgery, identification of the proximal RLN is generally not feasible. In patients with extensive node metastases, where the ipsilateral ansa cervicalis is unavailable, the contralateral ansa cervicalis could be transferred [146].

The success of reinnervation depends on how many axons connect with the adductor and abductor muscles [147]. Unfavorable synkinesis may occur during RLN repair [148]. This phenomenon is explained by the aberrant reinnervation of adductor/abductor fibers, which may be associated with worsening of the voice [145]. If synkinesis is present, subsequent medialization procedures or anastomosis of RLN sections may be applied to eliminate an undesirable voice outcome.

\section{E. Voice therapy \\ KQ 15. What is the role of voice therapy in patients with UVFP?}

\section{Recommendation 15}

(A) Voice therapy may be used to improve voice outcomes for patients with mild symptoms or if surgical medialization procedures are not available (strong recommendation, low-quality evidence).

(B) Voice therapy before and/or after surgical intervention is helpful for optimal postoperative phonation (strong recommendation, low-quality evidence).

\section{Supporting text}

Patients with UVFP experience different degrees of voice symptoms, depending on the position of the paralyzed vocal fold. Typically, they have a breathy voice. However, if the vocal fold is fixed in the medial position, their voice may not be compromised or they may present with diplophonia due to a difference between the level of the two vocal folds. Patients may use compensatory maneuvers to improve their vocal quality. These patterns, often called hyperfunctional symptoms, are a response to an underlying lack of glottal closure, and include constriction of the contralateral vocal folds and extrinsic laryngeal muscles, as well as increasing expiratory drive. These responses could lead to short-term improvements in voice quality, but are also associated with vocal fatigue and neck pain. Hyperfunctional patterns, which are likely to result in muscle tension dysphonia, are a primary cause of an effortful and strained voice during phonation, and eventually lead to worsening of voice quality and diminished patient satisfaction $[7,14,16,17,149,150]$.

For effective voice therapy planning, SLPs focus on two opposite mechanisms of voice production. The initial assessment should record the degree of vocal dysfunction, and differentiate potentially useful and undesirable compensatory strategies $[15,17]$. The goal of therapy is to improve glottal closure using appropriate compensatory mechanisms and to avoid undesirable compensatory behaviors, including anterior-posterior or lateral supraglottic constriction, falsetto voice, and pharyngeal muscle contraction [15-17,151].

In patients with mild symptoms and adequate airway protection, several options may be considered, including a wait-andsee approach, voice therapy, and medialization procedures (see KQ 5-15). Literature reviews have identified that voice therapy, as a stand-alone option for the treatment of UVFP, could be a good option even in these subsets of patients [152-155]. The committee recommends that patients receive voice therapy as early as possible, as long as there is no contraindication for this treatment and the patient desires to receive voice therapy [153]. According to the findings of modern neuropathophysiology, atrophic changes of muscle tones are correlated with the duration of the lack of muscle usage. Early intervention may prevent or delay muscle atrophy. The possible benefit from voice therapy can be determined after 1-2 sessions. Several studies have shown that 4-6 weeks is the minimum time required for patients to achieve a sustained benefit from voice therapy [156158]. However, for patients with a profound gap and/or aspiration, surgical medialization procedures (SMPs) are preferred (see KQ 16).

Even in such settings, a combination of both voice therapy and surgical treatment seems to be the best approach for treating UVFP.Voice therapy has been shown to be effective prior to SMPs. Preoperative voice therapy could relieve undesirable hyperfunctional symptoms, which may otherwise not be eliminated $[15,150]$. However, there are no published papers dealing 
with this topic, even though these approaches have been adopted at many institutions. SMPs may work as a stimulus after voice therapy, and postoperative voice therapy may be effective starting as soon as after swelling subsides after surgery. In such a setting, the goal of voice therapy is to help the patient to adapt to a new vocal production system after surgery $[159,160]$.

In general, voice therapy is classified into an indirect and a direct approach. Indirect therapy mainly consists of counseling regarding the voice production mechanism and educating patients about vocal hygiene. SLPs could help to decrease abnormal hyperfunctional symptoms, including throat clearing, coughing, and increased postural muscle tension [14-18]. Direct therapy aims to reduce the glottal gap, which include pushing methods, modification of expiratory drive, and adjustment of supraglottal pressure [16,161-165]. However, there is presently a lack of standardization in terms of methods for voice therapy and their clinical efficacy in dysphonia patients with UVFP [35,166]. Further research is needed to develop standardized evidence for the management of UVFP that incorporates controlled treatment protocols and more stringent clinical methodologies.

\section{F. Aspiration prevention}

KQ 16. Are medialization surgical procedures helpful for reducing aspiration in UVFP patients?

\section{Recommendation 16}

(A) Medialization surgical procedures can reduce the rates of penetration and aspiration in patients with acute or chronic UVFP (strong recommendation, moderate-quality evidence).

(B) If the patient is expected to be at risk for aspiration, medialization surgical procedures should be considered at the time of diagnosis (strong recommendation, moderatequality evidence).

\section{Supporting text}

Dysphagia in patients with UVFP can be induced by multiple causes, including reduced glottal competence and alterations of pharyngeal sensation. Especially for patients with UVFP due to central brain injuries or multiple cranial nerve palsies, dysphagia can result from more complex causes including oral phase abnormalities and poor coordination of deglutition, as well as mechanical protection $[167,168]$. However, several studies have reported that the addressing glottal incompetence leads to improvement of aspiration and penetration in these patients. SMPs including IL and MT (with or without AA) have shown promise as an effective means of restoring glottic competence, thereby potentially reducing the risk of aspiration and improving diet normalcy.

Carrau et al. [169] reported significant improvement of swallowing after LFS in 67 of 70 (96\%) patients with VFP who suf- fered from aspiration. In their series, $83 \%$ of patients demonstrated no signs of aspiration radiologically or clinically and $36 \%$ of patients with prior gastrostomy tube feedings could be converted to oral feeding after LFS [169]. In another study by Flint et al. [170], in which IL was administered to 84 patients, $94 \%$ of patients reported benefits in subjective symptoms such as management of secretions and thin liquids. Of 13 patients with severe dysphagia, nine patients were able to discontinue tube feeding and all alimentation was taken orally. However, SMPs may be not successful in the subset of patients with multiple cranial nerve injuries or altered pharyngeal sensation $[167,168]$.

\section{SUMMARY}

The management of UVFP should be tailored to the individual, taking into account the cause of paralysis, the resultant disability, and the patient's expectations. For all dysphonia patients, an endoscopic assessment of laryngeal structure and function should be performed to identify the degree of mobility of the vocal folds and the presence of laryngeal compensation in patients with UVFP. Stroboscopy is helpful to assess phonatory glottal closure, the mucosal wave, and the difference in level between vocal folds. However, physicians and SLPs should be cautious about using visualization tools as the sole indicator of outcomes. Instead, clinicians and SLPs should evaluate multidimensional aspects of voice, including various vocal features as well as patients' personal responses. Preoperative and postoperative voice assessments can be used to provide visual feedback to patients and physicians, thereby facilitating the establishment of an optimal treatment policy for UVFP. A basic set of parameters may be tailored according to the patient's capacity to participate effectively, as well as the examiner's facility with the assessment tool. When clinicians suspect a lesion along the RLN, imaging studies are also indicated. LEMG is useful for differentiating VFP due to mechanical causes, including arytenoid fixation or dislocation, in patients with UVFP and also provides prognostic information in terms of the recovery of neural function.

In most cases, recovery occurs within 6 months after injury, although some patients may also recover from 6 to 12 months. The effects of steroids on recovery in UVFP patients are still unclear; thus, routine prescription of systematic steroids is not recommended unless there are specific indications for this treatment.

Immediate reinnervation should be considered for direct laryngeal nerve injuries during surgery, whenever possible. For patients with a compensated voice and no aspiration, less invasive treatment, such as a wait-and-see approach, IL with temporary material, and voice therapy are applicable, depending on the patient's need or profession, but for patients with a high vocal demand, uncompensated voice, or aspiration/dysphagia, SMPs are preferred. A flowchart for the management of UVFP is depicted in Fig. 1. 

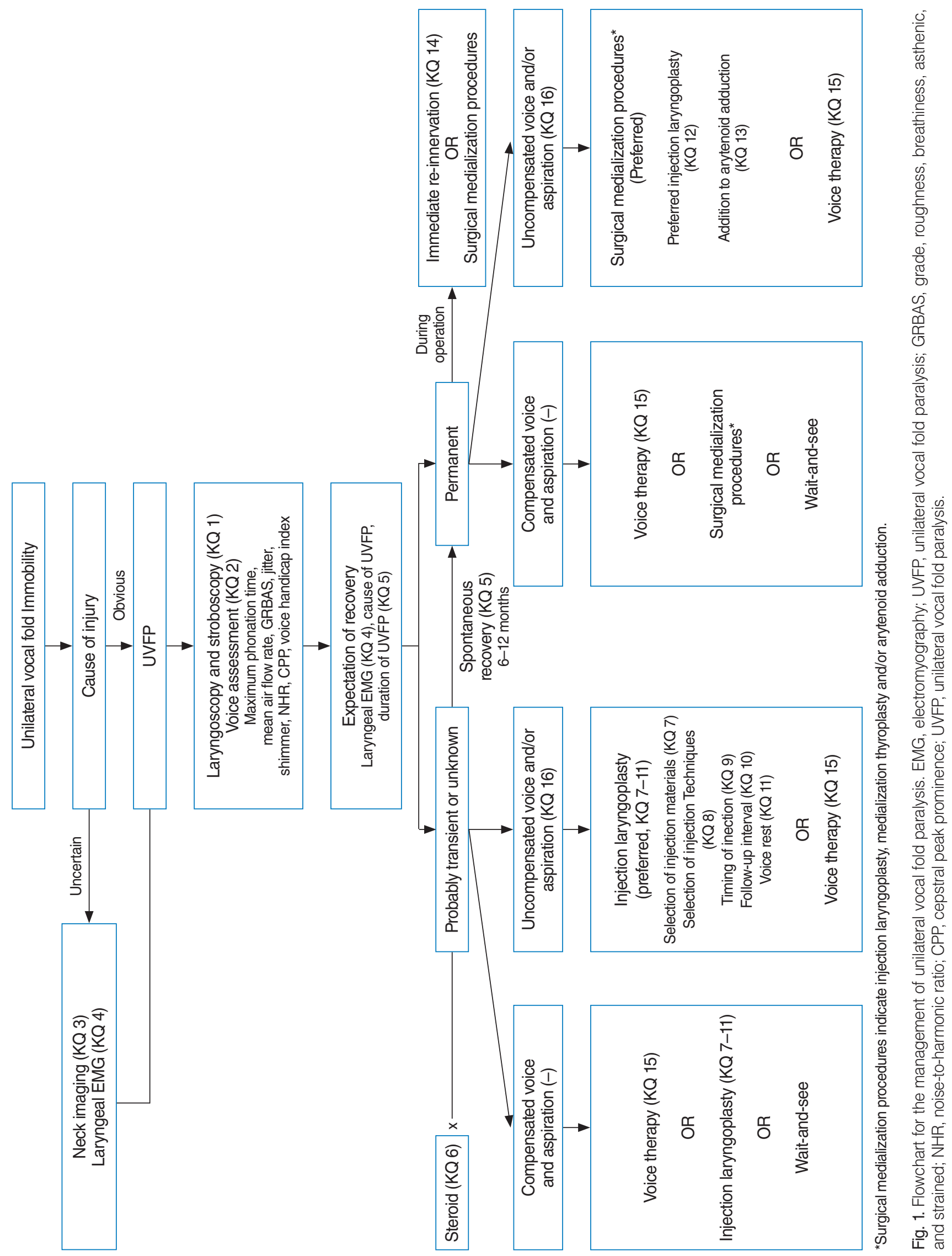

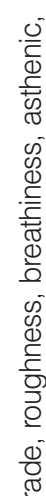




\section{CONFLICT OF INTEREST}

No potential conflict of interest relevant to this article was reported.

\section{ORCID}

Chang Hwan Ryu https://orcid.org/0000-0001-8150-5163

Tack-Kyun Kwon https://orcid.org/0000-0001-8250-914X

Heejin Kim

Han Su Kim

Il-Seok Park

Joo Hyun Woo

Sang-Hyuk Lee

Seung Won Lee

Jae-Yol Lim

Seong-Tae Kim

Sung-Min Jin

Seung Ho Choi https://orcid.org/0000-0001-6157-3636

https://orcid.org/0000-0003-2239-0225

https://orcid.org/0000-0001-8143-8968

https://orcid.org/0000-0002-8584-563X

https://orcid.org/0000-0003-4412-3486

https://orcid.org/0000-0002-0468-8143

https://orcid.org/0000-0002-3638-2632

https://orcid.org/0000-0003-2038-2862

https://orcid.org/0000-0003-0714-5862

https://orcid.org/0000-0001-9109-9621

\section{AUTHOR CONTRIBUTIONS}

Conceptualization: all authors. Data curation: all authors. Formal analysis: all authors. Methodology: CHR, SJJ, SHC. Project administration: CHR, SJJ, SHC. Writing-original draft: all authors. Writing-review \& editing: CHR, HJK, SJJ, SHC.

\section{SUPPLEMENTARY MATERIALS}

Supplementary materials can be available at https://doi.org/10. 21053/ceo.2020.00409.

\section{REFERENCES}

1. Nouraei SA, Middleton SE, Butler CR, Sandhu GS. An estimation of the population incidence of adult unilateral vocal fold mobility impairment in England. Logoped Phoniatr Vocol. 2015 Jul;40(2): 93-4.

2. Jellish WS, Jensen RL, Anderson DE, Shea JF. Intraoperative electromyographic assessment of recurrent laryngeal nerve stress and pharyngeal injury during anterior cervical spine surgery with Caspar instrumentation. J Neurosurg. 1999 Oct;91(2 Suppl):170-4.

3. Pisanu A, Porceddu G, Podda M, Cois A, Uccheddu A. Systematic review with meta-analysis of studies comparing intraoperative neuromonitoring of recurrent laryngeal nerves versus visualization alone during thyroidectomy. J Surg Res. 2014 May;188(1):152-61.

4. Crumley RL. Repair of the recurrent laryngeal nerve. Otolaryngol Clin North Am. 1990 Jun;23(3):553-63.

5. Mirza N, Ruiz C, Baum ED, Staab JP.The prevalence of major psychiatric pathologies in patients with voice disorders. Ear Nose Throat J. 2003 Oct;82(10):808-10.

6. Roy N, Merrill RM, Gray SD, Smith EM. Voice disorders in the general population: prevalence, risk factors, and occupational impact. Laryngoscope. 2005 Nov;115(11):1988-95.

7. Benninger MS, Ahuja AS, Gardner G, Grywalski C. Assessing outcomes for dysphonic patients. JVoice. 1998 Dec;12(4):540-50.

8. Stachler RJ, Francis DO, Schwartz SR, Damask CC, Digoy GP, Krouse HJ, et al. Clinical Practice Guideline: Hoarseness (Dysphonia) (Update). Otolaryngol Head Neck Surg. 2018 Mar;158(1_suppl):S1-S42.

9. Rosen CA, MauT, Remacle M, Hess M, Eckel HE, Young VN, et al. Nomenclature proposal to describe vocal fold motion impairment. Eur Arch Otorhinolaryngol. 2016 Aug;273(8):1995-9.

10. Qaseem A, Snow V, Owens DK, Shekelle P; Clinical Guidelines Committee of the American College of Physicians. The development of clinical practice guidelines and guidance statements of the American College of Physicians: summary of methods. Ann Intern Med. 2010 Aug;153(3):194-9.

11. Kim SY, Park JE, Lee YJ, Seo HJ, Sheen SS, Hahn S, et al. Testing a tool for assessing the risk of bias for nonrandomized studies showed moderate reliability and promising validity. J Clin Epidemiol. 2013 Apr;66(4):408-14.

12. Shea BJ, Grimshaw JM,Wells GA, Boers M,Andersson N, Hamel C, et al. Development of AMSTAR: a measurement tool to assess the methodological quality of systematic reviews. BMC Med Res Methodol. 2007 Feb;7:10.

13. Rosow DE, Sulica L. Laryngoscopy of vocal fold paralysis: evaluation of consistency of clinical findings. Laryngoscope. $2010 \mathrm{Jul}$;20(7): 1376-82.

14. Belafsky PC, Postma GN, Reulbach TR, Holland BW, Koufman JA. Muscle tension dysphonia as a sign of underlying glottal insufficiency. Otolaryngol Head Neck Surg. 2002 Nov;127(5):448-51.

15. Heuer RJ, Sataloff RT, Emerich K, Rulnick R, Baroody M, Spiegel $\mathrm{JR}$, et al. Unilateral recurrent laryngeal nerve paralysis: the importance of "preoperative" voice therapy. J Voice. 1997 Mar;11(1): 88-94.

16. Miller S. Voice therapy for vocal fold paralysis. Otolaryngol Clin North Am. 2004 Feb;37(1):105-19.

17. Rubin AD, Sataloff RT.Vocal fold paresis and paralysis. Otolaryngol Clin North Am. 2007 Oct;40(5):1109-31.

18. Sellars C, Carding PN, Deary IJ, MacKenzie K, Wilson JA. Characterization of effective primary voice therapy for dysphonia. J Laryngol Otol. 2002 Dec;116(12):1014-8.

19. Woodson GE. Configuration of the glottis in laryngeal paralysis. I: Clinical study. Laryngoscope. 1993 Nov;103(11 Pt 1):1227-34.

20. Hiramatsu H, Tokashiki R, Nakamura M, Motohashi R, Yoshida T, Suzuki M. Characterization of arytenoid vertical displacement in unilateral vocal fold paralysis by three-dimensional computed tomography. Eur Arch Otorhinolaryngol. 2009 Jan;266(1):97-104.

21. Paul BC, Rafii B, Achlatis S, Amin MR, Branski RC. Morbidity and patient perception of flexible laryngoscopy. Ann Otol Rhinol Laryngol. 2012 Nov;121(11):708-13.

22. Grossman M. Experimentelle beitrage zur lehre von der posticuslahmung. Arch Laryngol Rhinol. 1897;(6):282-360.

23. Wagner R. Die medianstellung des stimmbandes bei Recurrenslahmung. Archiv F Pathol Anat. 1890;120:437-9.

24. Behrman A. Evidence-based treatment of paralytic dysphonia: making sense of outcomes and efficacy data. Otolaryngol Clin North Am. 2004 Feb;37(1):75-104.

25. Woo P. Quantification of videostrobolaryngoscopic findings: measurements of the normal glottal cycle. Laryngoscope. 1996 Mar; 106(3 Pt 2 Suppl 79):1-27.

26. Sercarz JA, Berke GS, Ming Y, Gerratt BR, Natividad M.Videostroboscopy of human vocal fold paralysis. Ann Otol Rhinol Laryngol. 1992 Jul;101(7):567-77.

27. Wang W, Chen D, Chen S, Li D, Li M, Xia S, et al. Laryngeal rein- 
nervation using ansa cervicalis for thyroid surgery-related unilateral vocal fold paralysis: a long-term outcome analysis of 237 cases. PLoS One. 2011 Apr;6(4):e19128.

28. Harries ML, Morrison M.The role of stroboscopy in the management of a patient with a unilateral vocal fold paralysis. J Laryngol Otol. 1996 Feb;110(2):141-3.

29. Baylor CR, Yorkston KM, Eadie TL, Strand EA, Duffy J. A systematic review of outcome measurement in unilateral vocal fold paralysis. J Med Speech Lang Pathol. 2006 Mar;14(1):xxvii-lvii.

30. Bonilha HS, Focht KL, Martin-Harris B. Rater methodology for stroboscopy: a systematic review. JVoice. 2015 Jan;29(1):101-8.

31. Uloza V, Vegiene A, Saferis V. Correlation between the basic video laryngostroboscopic parameters and multidimensional voice measurements. JVoice. 2013 Nov;27(6):744-52.

32. Dejonckere PH, Bradley P, Clemente P, Cornut G, Crevier-Buchman L, Friedrich G, et al. A basic protocol for functional assessment of voice pathology, especially for investigating the efficacy of (phonosurgical) treatments and evaluating new assessment techniques. Guideline elaborated by the Committee on Phoniatrics of the European Laryngological Society (ELS). Eur Arch Otorhinolaryngol. $2001 \mathrm{Feb} ; 258(2): 77-82$.

33. Mattei A, Desuter G, Roux M, Lee BJ, Louges MA, Osipenko E, et al. International consensus (ICON) on basic voice assessment for unilateral vocal fold paralysis. Eur Ann Otorhinolaryngol Head Neck Dis. 2018 Feb;135(1S):S11-5.

34. Desuter G, Dedry M, Schaar B, van Lith-Bijl J, van Benthem PP, Sjogren EV. Voice outcome indicators for unilateral vocal fold paralysis surgery: a review of the literature. Eur Arch Otorhinolaryngol. 2018 Feb;275(2):459-68.

35. Walton C, Conway E, Blackshaw H, Carding P. Unilateral vocal fold paralysis: a systematic review of speech-language pathology management. JVoice. 2017 Jul;31(4):509.

36. Walton C, Carding P, Flanagan K. Perspectives on voice treatment for unilateral vocal fold paralysis. Curr Opin Otolaryngol Head Neck Surg. 2018 Jun;26(3):157-61.

37. Balasubramanium RK, Bhat JS, Fahim S 3rd, Raju R 3rd. Cepstral analysis of voice in unilateral adductor vocal fold palsy. J Voice. 2011 May;25(3):326-9.

38. Heman-Ackah YD. Reliability of calculating the cepstral peak without linear regression analysis. JVoice. 2004 Jun;18(2):203-8.

39. Lee CY, Jeong HS, Son HY. Usefulness of cepstral peak prominence (CPP) in unilateral vocal fold paralysis dysphonia evaluation. J Korean Soc Laryngol Phoniatr Logoped. 2017 Dec;28(2):84-8.

40. MacGregor FB, Roberts DN, Howard DJ, Phelps PD. Vocal fold palsy: a re-evaluation of investigations. J Laryngol Otol. 1994 Mar; 108(3):193-6.

41. Rosenthal LH, Benninger MS, Deeb RH. Vocal fold immobility: a longitudinal analysis of etiology over 20 years. Laryngoscope. 2007 Oct;117(10):1864-70.

42. Pretorius PM, Milford CA. Investigating the hoarse voice. BMJ. 2008 Oct;337:a1726.

43. Robinson S, Pitkaranta A. Radiology findings in adult patients with vocal fold paralysis. Clin Radiol. 2006 Oct;61(10):863-7.

44. Merati AL, Halum SL, Smith TL. Diagnostic testing for vocal fold paralysis: survey of practice and evidence-based medicine review. Laryngoscope. 2006 Sep;116(9):1539-52.

45. Sataloff RT, Praneetvatakul P, Heuer RJ, Hawkshaw MJ, Heman-Ackah YD, Schneider SM, et al. Laryngeal electromyography: clinical application. JVoice. 2010 Mar;24(2):228-34.

46. Wang CC, Chang MH, DeVirgilio A, Jiang RS, Lai HC, Wang CP, et al. Laryngeal electromyography and prognosis of unilateral vocal fold paralysis: a long-term prospective study. Laryngoscope. 2015 Apr;125(4):898-903.

47. Sulica L, Blitzer A. Electromyography and the immobile vocal fold.
Otolaryngol Clin North Am. 2004 Feb;37(1):59-74.

48. Heman-Ackah YD, Barr A.The value of laryngeal electromyography in the evaluation of laryngeal motion abnormalities. J Voice. 2006 Sep;20(3):452-60.

49. Focquet A, Pereon Y, Segura S, Ferron C, Malard O, Espitalier F. Diagnostic and prognostic contribution of laryngeal electromyography in unilateral vocal-fold immobility in adults. Eur Ann Otorhinolaryngol Head Neck Dis. 2017 Feb;134(1):13-8.

50. Volk GF, Hagen R, Pototschnig C, Friedrich G, Nawka T, Arens C, et al. Laryngeal electromyography: a proposal for guidelines of the European Laryngological Society. Eur Arch Otorhinolaryngol. 2012 Oct;269(10):2227-45.

51. Woo P, IsseroffTF, Parasher A, Richards A, Sivak M. Laryngeal Electromyographic findings in patients with vocal fold motion asymmetry. Laryngoscope. 2016 Aug;126(8):E273-7.

52. Wang CC, Chang MH, Jiang RS, Lai HC, DeVirgilio A, Wang CP, et al. Laryngeal electromyography-guided hyaluronic acid vocal fold injection for unilateral vocal fold paralysis: a prospective long-term follow-up outcome report. JAMA Otolaryngol Head Neck Surg. 2015 Mar;141(3):264-71.

53. Wang CC, Chang MH, Wang CP, Liu SA. Prognostic indicators of unilateral vocal fold paralysis. Arch Otolaryngol Head Neck Surg. 2008 Apr;134(4):380-8.

54. Munin MC, Heman-Ackah YD, Rosen CA, Sulica L, Maronian N, Mandel S, et al. Consensus statement: Using laryngeal electromyography for the diagnosis and treatment of vocal cord paralysis. Muscle Nerve. 2016 Jun;53(6):850-5.

55. Rickert SM, Childs LF, Carey BT, MurryT, Sulica L. Laryngeal electromyography for prognosis of vocal fold palsy: a meta-analysis. Laryngoscope. 2012 Jan;122(1):158-61.

56. Parnes SM, Satya-Murti S. Predictive value of laryngeal electromyography in patients with vocal cord paralysis of neurogenic origin. Laryngoscope. 1985 Nov;95(11):1323-6.

57. Seddon HJ. A classification of nerve injuries. Br Med J. 1942 Aug; 2(4260):237-9.

58. Sunderland S. A classification of peripheral nerve injuries producing loss of function. Brain. 1951 Dec;74(4):491-516.

59. Chen D, Chen S, Wang W, Zhang C, Zheng H. Spontaneous regeneration of recurrent laryngeal nerve following long-term vocal fold paralysis in humans: histologic evidence. Laryngoscope. 2011 May; 121(5):1035-9.

60. Mattsson P, Hydman J, Svensson M. Recovery of laryngeal function after intraoperative injury to the recurrent laryngeal nerve. Gland Surg. 2015 Feb;4(1):27-35.

61. Woodson GE. Spontaneous laryngeal reinnervation after recurrent laryngeal or vagus nerve injury. Ann Otol Rhinol Laryngol. 2007 Jan;116(1):57-65.

62. Sulica L. The natural history of idiopathic unilateral vocal fold paralysis: evidence and problems. Laryngoscope. 2008 Jul;118(7): 1303-7.

63. Husain S, Sadoughi B, Mor N, Levin AM, Sulica L. Time course of recovery of idiopathic vocal fold paralysis. Laryngoscope. 2018 Jan; 128(1):148-52.

64. MauT, Pan HM, Childs LF. The natural history of recoverable vocal fold paralysis: implications for kinetics of reinnervation. Laryngoscope. 2017 Nov;127(11):2585-90.

65. Cohen SM, Lee HJ, Roy N, Misono S. Pharmacologic management of voice disorders by general medicine providers and otolaryngologists. Laryngoscope. 2018 Mar;128(3):682-9.

66. Holland NJ,Weiner GM. Recent developments in Bell's palsy. BMJ. 2004 Sep;329(7465):553-7.

67. Stachler RJ, Chandrasekhar SS,Archer SM, Rosenfeld RM, Schwartz SR, Barrs DM, et al. Clinical practice guideline: sudden hearing loss. Otolaryngol Head Neck Surg. 2012 Mar;146(3 Suppl):S1-35. 
68. Wang LF, Lee KW, KuoWR, Wu CW, Lu SP, Chiang FY.The efficacy of intraoperative corticosteroids in recurrent laryngeal nerve palsy after thyroid surgery. World J Surg. 2006 Mar;30(3):299-303.

69. Cheng SP, Liu TP, Yang PS, Lee KS, Liu CL. Effect of perioperative dexamethasone on subjective voice quality after thyroidectomy: a meta-analysis and systematic review. Langenbecks Arch Surg. 2015 Dec;400(8):929-36.

70. Benninger MS. Acyclovir for the treatment of idiopathic vocal fold paralysis. Ear Nose Throat J. 1992 May;71(5):207-8.

71. Coleman C, Fozo M, Rubin A. Ramsay Hunt syndrome with severe dysphagia. JVoice. 2012 Jan;26(1):e27-8.

72. Dunn NM, Katial RK, Hoyte FC. Vocal cord dysfunction: a review. Asthma Res Pract. 2015 Sep;1:9.

73. Ichimura H, Ishikawa S, Yamamoto T, Onizuka M, Inadome Y, Noguchi $\mathrm{M}$, et al. Effectiveness of steroid treatment for hoarseness caused by idiopathic fibrosing mediastinitis: report of a case. Surg Today. 2006;36(4):382-4.

74. Kwon TK, Buckmire R. Injection laryngoplasty for management of unilateral vocal fold paralysis. Curr Opin Otolaryngol Head Neck Surg. 2004 Dec;12(6):538-42.

75. Tamura E, Fukuda H,Tabata Y. Intracordal injection technique: materials and injection site. Tokai J Exp Clin Med. 2008 Sep;33(3): $119-23$.

76. Verma SP, Dailey SH. Office-based injection laryngoplasty for the management of unilateral vocal fold paralysis. J Voice. 2014 May; 28(3):382-6.

77. DahlqvistA, Garskog O, Laurent C, Hertegard S, Ambrosio L, Borzacchiello A.Viscoelasticity of rabbit vocal folds after injection augmentation. Laryngoscope. 2004 Jan;114(1):138-42.

78. Arron ST, Neuhaus IM. Persistent delayed-type hypersensitivity reaction to injectable non-animal-stabilized hyaluronic acid. J Cosmet Dermatol. 2007 Sep;6(3):167-71.

79. Hertegard S, Hallen L, Laurent C, Lindstrom E, Olofsson K, Testad $\mathrm{P}$, et al. Cross-linked hyaluronan versus collagen for injection treatment of glottal insufficiency: 2-year follow-up. Acta Otolaryngol. 2004 Dec;124(10):1208-14.

80. Molteni G, Bergamini G, Ricci-Maccarini A, Marchese C, Ghidini A, Alicandri-Ciufelli M, et al. Auto-crosslinked hyaluronan gel injections in phonosurgery. Otolaryngol Head Neck Surg. 2010 Apr; 142(4):547-53.

81. Mallur PS, Rosen CA. Vocal fold injection: review of indications, techniques, and materials for augmentation. Clin Exp Otorhinolaryngol. 2010 Dec;3(4):177-82.

82. Kamer FM, Churukian MM. Clinical use of injectable collagen: a three-year retrospective review. Arch Otolaryngol. 1984 Feb;110(2): 93-8.

83. Bentkover SH. The biology of facial fillers. Facial Plast Surg. 2009 May;25(2):73-85.

84. Milstein CF,Akst LM, Hicks MD, Abelson TI, Strome M. Long-term effects of micronized Alloderm injection for unilateral vocal fold paralysis. Laryngoscope. 2005 Sep;115(9):1691-6.

85. Tan M, Woo P. Injection laryngoplasty with micronized dermis: a 10-year experience with 381 injections in 344 patients. Laryngoscope. 2010 Dec;120(12):2460-6.

86. Chhetri DK, Jahan-Parwar B, Hart SD, Bhuta SM, Berke GS. Injection laryngoplasty with calcium hydroxylapatite gel implant in an in vivo canine model. Ann Otol Rhinol Laryngol. 2004 Apr;113(4): 259-64.

87. Rosen CA, Gartner-Schmidt J, Casiano R, Anderson TD, Johnson F, Remacle M, et al. Vocal fold augmentation with calcium hydroxylapatite: twelve-month report. Laryngoscope. 2009 May;119(5): 1033-41.

88. CarrollTL, Rosen CA. Long-term results of calcium hydroxylapatite for vocal fold augmentation. Laryngoscope. 2011 Feb;121(2):313-9.
89. Tanna N, Zalkind D, Glade RS, Bielamowicz SA. Foreign body reaction to calcium hydroxylapatite vocal fold augmentation. Arch Otolaryngol Head Neck Surg. 2006 Dec;132(12):1379-82.

90. Won SJ, Woo SH. Calcium hydroxylapatite pulmonary embolism after percutaneous injection laryngoplasty. Yonsei Med J. 2017 Nov; 58(6):1245-8.

91. Min JY, Hong SD, Kim K, Son YI. Long-term results of Artecoll injection laryngoplasty for patients with unilateral vocal fold motion impairment: safety and clinical efficacy. Arch Otolaryngol Head Neck Surg. 2008 May;134(5):490-6.

92. Sulica L, Rosen CA, Postma GN, Simpson B, Amin M, Courey M, et al. Current practice in injection augmentation of the vocal folds: indications, treatment principles, techniques, and complications. Laryngoscope. 2010 Feb;120(2):319-25.

93. Mathison CC, Villari CR, Klein AM, Johns MM 3rd. Comparison of outcomes and complications between awake and asleep injection laryngoplasty: a case-control study. Laryngoscope. 2009 Jul;119(7): 1417-23.

94. Young VN, Smith LJ, Sulica L, Krishna P, Rosen CA. Patient tolerance of awake, in-office laryngeal procedures: a multi-institutional perspective. Laryngoscope. 2012 Feb;122(2):315-21.

95. Costello D. Change to earlier surgical interventions: contemporary management of unilateral vocal fold paralysis. Curr Opin Otolaryngol Head Neck Surg. 2015 Jun;23(3):181-4.

96. Soriano RG, Pei YC, Fang TJ. In-office hyaluronate injection laryngoplasty as palliative treatment for unilateral vocal fold paralysis. ORL J Otorhinolaryngol Relat Spec. 2016;78(4):187-92.

97. Chun BJ, Shim MR, Hwang YS, Joo YH, Park YH, Sun DI. The usefulness of the transcricothyroid injection laryngoplasty via contralateral paramedian approach. Auris Nasus Larynx. 2017 Feb;44(1): 93-7.

98. Woo SH, Son YI, Lee SH, Park JJ, Kim JP. Comparative analysis on the efficiency of the injection laryngoplasty technique using calcium hydroxyapatite (CaHA): the thyrohyoid approach versus the cricothyroid approach. JVoice. 2013 Mar;27(2):236-41.

99. Tirado Y, Lewin JS, Hutcheson KA, Kupferman ME. Office-based injection laryngoplasty in the irradiated larynx. Laryngoscope. 2010 Apr;120(4):703-6.

100. Graboyes EM, Bradley JP, Meyers BF, Nussenbaum B. Efficacy and safety of acute injection laryngoplasty for vocal cord paralysis following thoracic surgery. Laryngoscope. 2011 Nov;121(11):2406-10.

101. Vila PM, Bhatt NK, Paniello RC. Early-injection laryngoplasty may lower risk of thyroplasty: a systematic review and meta-analysis. Laryngoscope. 2018 Apr;128(4):935-40.

102. Pei YC, Fang TJ, Hsin LJ, Li HY,Wong AM. Early hyaluronate injection improves quality of life but not neural recovery in unilateral vocal fold paralysis: an open-label randomized controlled study. Restor Neurol Neurosci. 2015;33(2):121-30.

103. Powell J, Carding P, Birdi R, Wilson JA. Injection laryngoplasty in the outpatient clinic under local anaesthetic: a case series of sixtyeight patients. Clin Otolaryngol. 2014 Aug;39(4):224-7.

104. Rosen CA. Complications of phonosurgery: results of a national survey. Laryngoscope. 1998 Nov;108(11 Pt 1):1697-703.

105. Mohammed H, Masterson L, Gendy S, Nassif R. Outpatient-based injection laryngoplasty for the management of unilateral vocal fold paralysis: clinical outcomes from a UK centre. Clin Otolaryngol. 2016 Aug;41(4):341-6.

106. Anderson TD, Sataloff RT. Complications of collagen injection of the vocal fold: report of several unusual cases and review of the literature. JVoice. 2004 Sep;18(3):392-7.

107. DeFatta RA, Chowdhury FR, Sataloff RT. Complications of injection laryngoplasty using calcium hydroxylapatite. J Voice. 2012 Sep;26(5):614-8.

108. Alghonaim Y, Roskies M, Kost K, Young J. Evaluating the timing of 
injection laryngoplasty for vocal fold paralysis in an attempt to avoid future type 1 thyroplasty. J Otolaryngol Head Neck Surg. 2013 Mar;42(1):24.

109. Fang TJ, Pei YC, Li HY, Wong AM, Chiang HC. Glottal gap as an early predictor for permanent laryngoplasty in unilateral vocal fold paralysis. Laryngoscope. 2014 Sep;124(9):2125-30.

110. Friedman AD, Burns JA, Heaton JT, Zeitels SM. Early versus late injection medialization for unilateral vocal cord paralysis. Laryngoscope. 2010 Oct;120(10):2042-6.

111. Halderman AA, Bryson PC, Benninger MS, Chota R. Safety and length of benefit of restylane for office-based injection medialization-a retrospective review of one institution's experience. J Voice. 2014 Sep;28(5):631-5.

112. Prendes BL, Yung KC, Likhterov I, Schneider SL, Al-Jurf SA, Courey MS. Long-term effects of injection laryngoplasty with a temporary agent on voice quality and vocal fold position. Laryngoscope. 2012 Oct;122(10):2227-33.

113. Yung KC, Likhterov I, Courey MS. Effect of temporary vocal fold injection medialization on the rate of permanent medialization laryngoplasty in unilateral vocal fold paralysis patients. Laryngoscope. 2011 Oct;121(10):2191-4.

114. Brandenburg JH, Kirkham W, Koschkee D. Vocal cord augmentation with autogenous fat. Laryngoscope. 1992 May;102(5):495-500.

115. Kwon TK, An SY, Ahn JC, Kim KH, Sung MW. Calcium hydroxylapatite injection laryngoplasty for the treatment of presbylaryngis: long-term results. Laryngoscope. 2010 Feb;120(2):326-9.

116. Pagano R, Morsomme D, Camby S, Lejeune L, Finck C. Long-term results of 18 fat injections in unilateral vocal fold paralysis. JVoice. 2017 Jul;31(4):505.

117. Rosen CA, Thekdi AA.Vocal fold augmentation with injectable calcium hydroxylapatite: short-term results. J Voice. 2004 Sep;18(3): 387-91.

118. Trask DK, Shellenberger DL, Hoffman HT. Transnasal, endoscopic vocal fold augmentation. Laryngoscope. 2005 Dec;115(12):2262-5.

119. Szkielkowska A, Miaskiewicz B, Remacle M, Krasnodebska P, Skarzynski H. Quality of the voice after injection of hyaluronic acid into the vocal fold. Med Sci Monit. 2013 Apr;19:276-82.

120. Andrews BT, Van Daele DJ, Karnell MP, McCulloch TM, Graham SM, Hoffman HT. Evaluation of open approach and injection laryngoplasty in revision thyroplasty procedures. Otolaryngol Head Neck Surg. 2008 Feb;138(2):226-32.

121. ShenT, Damrose EJ, Morzaria S. A meta-analysis of voice outcome comparing calcium hydroxylapatite injection laryngoplasty to silicone thyroplasty. Otolaryngol Head Neck Surg. 2013 Feb;148(2): 197-208.

122. Siu J, Tam S, Fung K. A comparison of outcomes in interventions for unilateral vocal fold paralysis: a systematic review. Laryngoscope. 2016 Jul;126(7):1616-24.

123. Cantillo-Banos E, Jurado-Ramos A, Gutierrez-Jodas J,Ariza-Vargas L. Vocal fold insufficiency: medialization laryngoplasty vs calcium hydroxylapatite microspheres (Radiesse Voice ${ }^{\circledR}$ ). Acta Otolaryngol. 2013 Mar;133(3):270-5.

124. Umeno H, Chitose S, Sato K, Ueda Y, Nakashima T. Long-term postoperative vocal function after thyroplasty type I and fat injection laryngoplasty. Ann Otol Rhinol Laryngol. 2012 Mar;121(3): 185-91.

125. Umeno H, Chitose S, Sato K, Nakashima T. Comparative study of framework surgery and fat injection laryngoplasty. J Laryngol Otol Suppl. 2009:35-41.

126. Abraham MT, Gonen M, Kraus DH. Complications of type I thyroplasty and arytenoid adduction. Laryngoscope. 2001 Aug;111(8): 1322-9.

127. Kwon M, Choi SH. Transoral arytenoid adduction with minimal cervical incision. Laryngoscope. 2015 May;125(5):1172-4.
128. Murata T, Yasuoka Y, Shimada T, Shino M, Iida H,Takahashi K, et al. A new and less invasive procedure for arytenoid adduction surgery: endoscopic-assisted arytenoid adduction surgery. Laryngoscope. 2011 Jun;121(6):1274-80.

129. Young VN, Zullo TG, Rosen CA. Analysis of laryngeal framework surgery: 10-year follow-up to a national survey. Laryngoscope. 2010 Aug;120(8):1602-8.

130. Kupferman ME, Acevedo J, Hutcheson KA, Lewin JS. Addressing an unmet need in oncology patients: rehabilitation of upper aerodigestive tract function. Ann Oncol. 2011 Oct;22(10):2299-303.

131. Daniero JJ, Garrett CG, Francis DO. Framework surgery for treatment of unilateral vocal fold paralysis. Curr Otorhinolaryngol Rep. 2014 Jun;2(2):119-30.

132. Isshiki N, Okamura H, Ishikawa T. Thyroplasty type I (lateral compression) for dysphonia due to vocal cord paralysis or atrophy. Acta Otolaryngol. 1975 Nov-Dec;80(5-6):465-73.

133. Isshiki N,Tanabe M, Sawada M.Arytenoid adduction for unilateral vocal cord paralysis. Arch Otolaryngol. 1978 Oct;104(10):555-8.

134. Chester MW, Stewart MG. Arytenoid adduction combined with medialization thyroplasty: an evidence-based review. Otolaryngol Head Neck Surg. 2003 Oct;129(4):305-10.

135. Hess MM, Fleischer S. Laryngeal framework surgery: current strategies. Curr Opin Otolaryngol Head Neck Surg. 2016 Dec;24(6): 505-9.

136. Li AJ, Johns MM, Jackson-Menaldi C, Dailey S, Heman-Ackah Y, Merati A, et al. Glottic closure patterns: type I thyroplasty versus type I thyroplasty with arytenoid adduction. J Voice. 2011 May; 25(3):259-64.

137. Mortensen M, Carroll L, Woo P. Arytenoid adduction with medialization laryngoplasty versus injection or medialization laryngoplasty: the role of the arytenoidopexy. Laryngoscope. 2009 Apr;119(4): 827-31.

138. Chang J, Schneider SL, Curtis J, Langenstein J, Courey MS, Yung KC. Outcomes of medialization laryngoplasty with and without arytenoid adduction. Laryngoscope. 2017 Nov;127(11):2591-5.

139. KumaiY, Kodama N, Murakami D, Yumoto E. Comparison of vocal outcome following two different procedures for immediate RLN reconstruction. Eur Arch Otorhinolaryngol. 2016 Apr;273(4):967-72.

140. Chou FF, Su CY, Jeng SF, Hsu KL, Lu KY. Neurorrhaphy of the recurrent laryngeal nerve. J Am Coll Surg. 2003 Jul;197(1):52-7.

141. Lee SW, Park KN, Oh SK, Jung CH, Mok JO, Kim CH. Long-term efficacy of primary intraoperative recurrent laryngeal nerve reinnervation in the management of thyroidectomy-related unilateral vocal fold paralysis. Acta Otolaryngol. 2014 Nov;134(11):1179-84.

142. Lee SW, Park KN. A long-term comparative prospective study between reinnervation and injection laryngoplasty. Laryngoscope. 2018 Aug;128(8):1893-7.

143. Lorenz RR, Esclamado RM, Teker AM, Strome M, Scharpf J, Hicks $\mathrm{D}$, et al. Ansa cervicalis-to-recurrent laryngeal nerve anastomosis for unilateral vocal fold paralysis: experience of a single institution. Ann Otol Rhinol Laryngol. 2008 Jan;117(1):40-5.

144. Yumoto E, SanukiT, Kumai Y. Immediate recurrent laryngeal nerve reconstruction and vocal outcome. Laryngoscope. 2006 Sep;116(9): 1657-61.

145. Aynehchi BB, McCoul ED, Sundaram K. Systematic review of laryngeal reinnervation techniques. Otolaryngol Head Neck Surg. 2010 Dec;143(6):749-59.

146. Miyauchi A, Yokozawa T, Kobayashi K, Hirai K, Matsuzuka F, Kuma $\mathrm{K}$. Opposite ansa cervicalis to recurrent laryngeal nerve anastomosis to restore phonation in patients with advanced thyroid cancer. Eur J Surg. 2001 Jul;167(7):540-1.

147. Paniello RC. Laryngeal reinnervation. Otolaryngol Clin North Am. 2004 Feb;37(1):161-81.

148. Crumley RL. Laryngeal synkinesis revisited. Ann Otol Rhinol Lar- 
yngol. 2000 Apr;109(4):365-71.

149. Kelchner LN, Lee L, Stemple JC. Laryngeal function and vocal fatigue after prolonged reading in individuals with unilateral vocal fold paralysis. JVoice. 2003 Dec;17(4):513-28.

150. Schneider B, Schickinger-Fischer B, Zumtobel M, Mancusi G, Bigenzahn W, Klepetko W, et al. Concept for diagnosis and therapy of unilateral recurrent laryngeal nerve paralysis following thoracic surgery. Thorac Cardiovasc Surg. 2003 Dec;51(6):327-31.

151. Aronson AE. Clinical voice disorders. New York: Thieme Medical Publishers; 1990.

152. Kao YC, Chen SH, Wang YT, Chu PY, Tan CT, Chang WD. Efficacy of voice therapy for patients with early unilateral adductor vocal fold paralysis. JVoice. 2017 Sep;31(5):567-75.

153. Mattioli F, Menichetti M, Bergamini G, Molteni G, Alberici MP, Luppi MP, et al. Results of early versus intermediate or delayed voice therapy in patients with unilateral vocal fold paralysis: our experience in 171 patients. JVoice. 2015 Jul;29(4):455-8.

154. Schindler A, Bottero A, Capaccio P, Ginocchio D, Adorni F, Ottaviani $F$. Vocal improvement after voice therapy in unilateral vocal fold paralysis. JVoice. 2008 Jan;22(1):113-8.

155. Lee CY, An SY, Chang H, Son HY. Comparison of initial therapeutic effects of voice therapy and injection laryngoplasty for unilateral vocal cord paralysis patients. J Korean Soc Laryngol Phoniatr Logoped. 2017 Dec;28(2):112-7.

156. Roy N, Gray SD, Simon M, Dove H, Corbin-Lewis K, Stemple JC. An evaluation of the effects of two treatment approaches for teachers with voice disorders: a prospective randomized clinical trial. J Speech Lang Hear Res. 2001 Apr;44(2):286-96.

157. Sabol JW, Lee L, Stemple JC. The value of vocal function exercises in the practice regimen of singers. JVoice. 1995 Mar;9(1):27-36.

158. Stemple JC, Lee L, D'Amico B, Pickup B. Efficacy of vocal function exercises as a method of improving voice production. JVoice. 1994 Sep;8(3):271-8.

159. Isshiki N. Mechanical and dynamic aspects of voice production as related to voice therapy and phonosurgery. Otolaryngol Head Neck Surg. 2000 Jun;122(6):782-93.

160. Isshiki N. Mechanical and dynamic aspects of voice production as related to voice therapy and phonosurgery. JVoice. 1998 Jun;12(2): 125-37.

161. Bailey EF, Hoit JD. Speaking and breathing in high respiratory drive. J Speech Lang Hear Res. 2002 Feb;45(1):89-99.

162. MacLarnon AM, Hewitt GP. The evolution of human speech: the role of enhanced breathing control. Am J Phys Anthropol. 1999 Jul; 109(3):341-63.

163. Russell BA, Cerny FJ, Stathopoulos ET. Effects of varied vocal intensity on ventilation and energy expenditure in women and men. J Speech Lang Hear Res. 1998 Apr;41(2):239-48.

164. Verdolini K, Druker DG, Palmer PM, Samawi H. Laryngeal adduction in resonant voice. JVoice. 1998 Sep;12(3):315-27.

165. Yamaguchi H,Yotsukura Y, Sata H,Watanabe Y, Hirose H, Kobayashi $\mathrm{N}$, et al. Pushing exercise program to correct glottal incompetence. JVoice. 1993 Sep;7(3):250-6.

166. Speyer R. Effects of voice therapy: a systematic review. JVoice. 2008 Sep;22(5):565-80.

167. Damrose EJ. Percutaneous injection laryngoplasty in the management of acute vocal fold paralysis. Laryngoscope. 2010 Aug;120(8): 1582-90.

168. Bhattacharyya N, Kotz T, Shapiro J. Dysphagia and aspiration with unilateral vocal cord immobility: incidence, characterization, and response to surgical treatment. Ann Otol Rhinol Laryngol. 2002 Aug;111(8):672-9.

169. Carrau RL, Pou A, Eibling DE, Murry T, Ferguson BJ. Laryngeal framework surgery for the management of aspiration. Head Neck. 1999 Mar;21(2):139-45.

170. Flint PW, Purcell LL, Cummings CW. Pathophysiology and indications for medialization thyroplasty in patients with dysphagia and aspiration. Otolaryngol Head Neck Surg. 1997 Mar;116(3):349-54. 